\title{
Polymer Electrolyte Fuel Cell Degradation Mechanisms and Their Diagnosis by Frequency Response Analysis Methods: A Review
}

\author{
Antonio Sorrentino ${ }^{1}$, Kai Sundmacher ${ }^{1,2}$ and Tanja Vidakovic-Koch ${ }^{1, *(D)}$ \\ 1 Max Planck Institute for Dynamics of Complex Technical Systems, Sandtorstraße 1, \\ D-39106 Magdeburg, Germany; sorrentino@mpi-magdeburg.mpg.de (A.S.); \\ kai@mpi-magdeburg.mpg.de (K.S.) \\ 2 Otto-von-Guericke University Magdeburg, Process Systems Engineering, Universitätsplatz 2, \\ D-39106 Magdeburg, Germany \\ * Correspondence: vidakovic@mpi-magdeburg.mpg.de
}

Received: 30 September 2020; Accepted: 2 November 2020; Published: 8 November 2020

\begin{abstract}
Several experimental techniques involving dynamic electrical variables are used to study the complex behaviour of polymer electrolyte membrane fuel cells in order to improve performance and durability. Among them, electrochemical impedance spectroscopy (EIS) is one of the most employed methods. Like any frequency response analysis (FRA) methodology, EIS enables one to separate the contribution of many processes to performance losses. However, it fails to identify processes with a similar time constant and the interpretation of EIS spectra is often ambiguous. In the last decade, alternative FRA methodologies based on non-electrical inputs and/or outputs have been developed. These studies were mainly driven by requirements for a better diagnosis of polymer electrolyte membrane fuel cells (PEMFCs) faulty operation conditions as well as better component and material design. In this contribution, a state-of-the-art EIS and novel FRA techniques for PEMFC diagnosis are summarised. First, common degradation mechanisms and their causes are discussed. A mathematical framework based on linear system theory of time invariant systems is described in order to explain the theoretical implications of the use of different input/output configurations. In relation to this, the concepts and potential are depicted as well as the problematic aspects and future prospective of these diagnostic approaches.
\end{abstract}

Keywords: polymer electrolyte membrane fuel cell; degradation; impedance; frequency response analysis; PEMFC diagnosis

\section{Introduction}

Polymer electrolyte membrane fuel cells (PEMFCs) are one of the cornerstones of electromobility. Additionally they are considered for stationary applications (heat and electricity supply). However, prolonged use can expose them to several degradation mechanisms that deteriorates the physical and chemical stability of different components causing a reversible or irreversible lowering of the performance and decrement of the cell lifetime. The damaging action of these phenomena is accelerated by operating the cell under certain faulty conditions. The main ones are the flooding of the electrodes, dehydration, reactants starvation, and presence of impurities in fuel or oxidant feeds.

Two main strategies have been adopted in order to mitigate the effects of degradation: (i) The improvement of the cell components through design optimisation and search for more stable and resistant materials, and (ii) the development of online diagnostic tools to identify faulty conditions and correct them during operations. With respect to the latter approach, due to the considerable 
number of phenomena taking place in PEMFCs, a diagnostic tool should have the capability to identify and evaluate the effect of a specific phenomenon on the performance. As it is well known, frequency response analysis (FRA) fulfils this requirement. Among others, electrochemical impedance spectroscopy (EIS) is the most applied FRA technique in electrochemistry. EIS can separate the contributions of different physicochemical processes occurring in a generic electrochemical system to performance losses. In EIS, an electrochemical system is excited by a sinusoidal electric input (current or cell potential) at different frequencies and the complementary electric output is measured. This way, the related transfer functions commonly known by the name of impedance/admittance are obtained. By evaluating values of impedance in different frequency regions of the obtained EIS spectra, it is possible to identify and quantify the resistances due to a certain phenomenon or component. For a meaningful analysis, the amplitude of the electric stimulation must be small enough to assure a linear response free from nonlinearities, which could lead to wrong conclusions. Other requirements for correct EIS analysis is the stability of the system, which must be in steady state during the execution of the experiment, and the causality meaning that the current response (or voltage) must be a direct consequence of the voltage (or current) perturbation.

The presence of well-established hardware for EIS developed for previous applications of impedance techniques in electrical engineering is one of the main reasons for the success of this characterisation method. Many EIS applications for PEMFC are reviewed in several publications [1-4]. However, EIS often fails to separate contributions of processes having comparable time constants, making it a challenge for the interpretation of the spectra and a meaningful quantitative analysis. For this reason, alternative techniques have been proposed aimed at decoupling the single process contribution. Some examples are: The estimation of the relaxation time distribution (RTD) [5], total harmonic distortion [6], and nonlinear EIS (nEIS) [7].

All the mentioned methods are based on analysis of both electrical input and as well as output. Recently, several FRA methodologies based on the use of nonelectric input and/or output have been proposed for the study of PEMFCs [8-18]. The idea motivating their development is that by stimulating the cell through a specific nonelectrical variable instead of an electrical one, a response containing information on the dynamics of a single or few processes could be generated. In this review, state-of-the-art FRA methodologies applied to study of PEMFCs is presented starting from EIS to novel ones. The advantages are the challenges as well as the possible improvement of new FRA techniques discussed in a systematic way.

The paper is divided in two parts. In the first section, the most common degradation mechanisms are discussed to give an idea of the complexity of the many processes interacting in parallel in a PEMFC as well as to motivate the need for more specific FRA techniques. In the second section, a mathematical framework based on linear system theory (LST) of time invariant systems is described in order to clarify the implications of the use of different input/output configurations and to illustrate how the information related to a certain phenomena present in the resulting transfer function can be theoretically evaluated. Then, the strategies of using EIS for material and design optimisation and as a real-time monitoring diagnostic tool are exposed as well as the state of the interpretation of the EIS spectra. In the latter part an emphasis was on overlapping different contributions in EIS spectra as well as on unexplained patterns. Finally, in the last section the new FRA methods involving different nonelectrical input/output are reviewed. In the summary, problematic aspects and a future prospective of the latter diagnostic approach are discussed.

\section{Faulty Conditions and Degradation Mechanisms}

Steady state and dynamic operating regimes under faulty conditions speed up degradation. A schematic depicting the relations between the main faulty states, degradation mechanisms, and their irreversible consequences on the cell is depicted in Figure 1. The most relevant faulty conditions for stationary and mobile applications of PEMFCs include poor water management (flooding or drying out), reactants starvation, and the presence of contaminants in the fuel and in oxidant streams. 


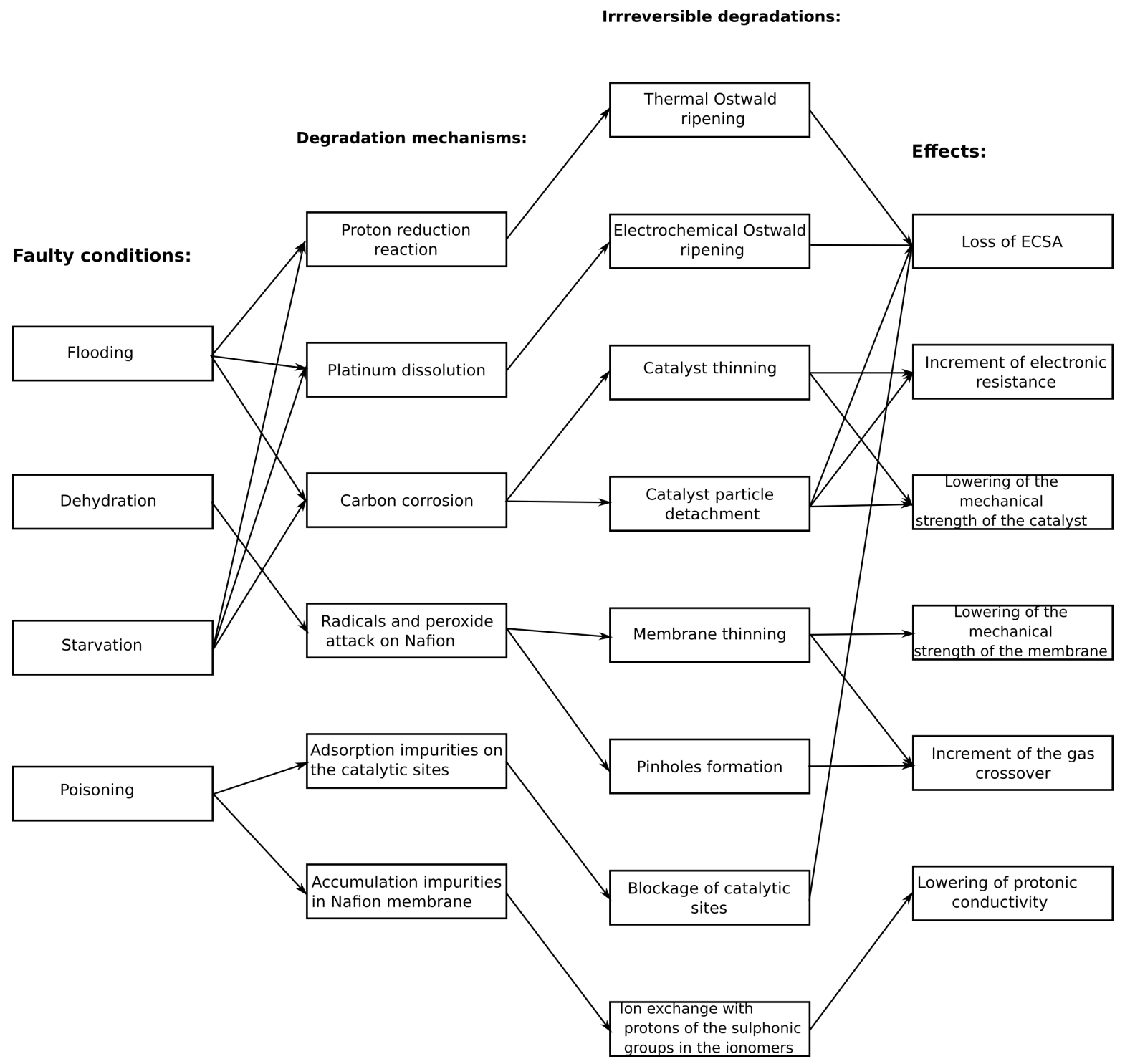

Figure 1. Schematic of the relations between faulty conditions, degradation mechanisms, irreversible degradation, and their effect.

\subsection{Performance Losses and Degradation Mechanisms Associated to Flooding}

Flooding is caused by water condensation and accumulation inside the porous structure of the electrode. As a consequence, the path of the oxygen to the catalyst is hindered and the mass transport resistance dramatically increases. In the most critical situation, entire sections of the catalyst layer become inaccessible to the gaseous species and a shut down of the operation can occur in an extreme case if the current demanded from the control unit could not be supplied. The cathode side is generally more prone to flooding due to the continuous production of water through the oxygen reduction reaction (ORR) [19]. However, the anode is often flooded under operating conditions where the back diffusion is dominant with respect to the osmotic flow [20,21], as well as in fuel cells operating in dead end mode [22].

Long term operations or dynamic load changes under flooded conditions lead to the degradation of electrodes. Variations of the overpotential at the catalyst interface in the starved regions of the cell favour the progression of side reactions modifying irreversibly the morphology and chemical composition of the catalyst $[23,24]$. On the cathode side, the depletion of oxygen arising in the flooded area of the electrode causes a local potential decrement achieving a value lower than the 
anode equilibrium potential $[25,26]$. Under these conditions, the oxygen reduction is replaced by the hydrogen evolution reaction:

$$
2 \mathrm{H}_{3} \mathrm{O}^{+}+2 \mathrm{e}^{-}=\mathrm{H}_{2}+2 \mathrm{H}_{2} \mathrm{O} \quad\left(\mathrm{E}^{0}=0.00 \mathrm{~V}\right) .
$$

The reversal current generated by this reaction results in an inhomogeneous current distribution that increases in the not starved area of the catalyst surface in order to keep the total current value demanded by the electrical control applied to the cell. As a consequence, there is a significant temperature increase in catalyst parts supplying higher current densities. This enhances the agglomeration of platinum particles and finally causes a local reduction of the electrochemically-active surface area (ECSA) available for the ORR.

On the anode side, a decrease of hydrogen partial pressure in the flooded region causes an increase of local electrode potential. Then, the current redistributes with a higher local current density in the regions of lower anode overpotential (non-flooded regions). This redistribution impacts the corresponding cathode regions on the opposite side where the local ORR overpotential and ohmic drop decrease. The lower local overpotentials (more positive cathode potentials) in these parts of the cathode catalyst layer favour the platinum catalyst dissolution as well as carbon corrosion.

The platinum dissolution in PEMFCs has been proven to occur either through the direct dissolution of the metal:

$$
\mathrm{Pt}=\mathrm{Pt}^{2+}+2 \mathrm{e}^{-} \quad\left(\mathrm{E}^{0}=1.19+0.029 \log \left[\mathrm{Pt}^{+}\right]\right)
$$

or by the first formation of an oxide layer and subsequent oxide dissolution:

$$
\begin{aligned}
\mathrm{Pt}+\mathrm{H}_{2} \mathrm{O} & =\mathrm{PtO}+2 \mathrm{H}^{+}+2 \mathrm{e}^{-} \quad\left(\mathrm{E}^{0}=0.98+0.59 \mathrm{pH}\right) \\
\mathrm{PtO}+2 \mathrm{H}^{+} & =\mathrm{Pt}^{2+}+\mathrm{H} 2 \mathrm{O} \quad\left(\log \left[\mathrm{Pt}^{2+}\right]=-7.06+2 \mathrm{pH}\right) .
\end{aligned}
$$

Pt metal is fairly stable in the ionomeric phase for an acidic $\mathrm{pH}$ and an electrochemical potential below $0.9 \mathrm{~V}$ at $25^{\circ} \mathrm{C}$ [27]. Above this potential $\mathrm{Pt}^{2+}$ and $\mathrm{PtO}$ are more stable and the corrosion of $\mathrm{Pt}$ through the steps (2)-(4) is thermodynamically favoured. However, the reaction (4) is extremely slow so that the formation of a platinum oxide layer protects the catalyst against dissolution, which practically takes place only through step (2). Smaller Pt particles tend to dissolve preferentially, as their chemical potential is higher than the chemical potential of bigger particles. The dissolved Pt ions migrate to the surface of the larger particles. This dissolution redeposition process named electrochemical Ostwald ripening favours the growth of bigger particles lowering irreversibly the available ECSA and increasing kinetic resistance. Pt dissolution dramatically accelerates under dynamic conditions resulting often in sudden voltage changes [28-30]. This is due to the fact that a rapid rise or lowering of the voltage favours the platinum dissolution (Equation (2)) which is faster than the formation of a protective oxide layer (Equation (3)). This phenomenon leads to significant losses of ECSA over repeated voltage cycling [31].

The general carbon corrosion reaction in the aqueous solution can be expressed by the following equation:

$$
\mathrm{C}+\mathrm{H}_{2} \mathrm{O}=\mathrm{CO}_{2}+4 \mathrm{H}^{+}+4 \mathrm{e}^{-} \quad\left(\mathrm{E}^{0}=0.207\right)
$$

As the equilibrium electrode potentials of the carbon corrosion reaction is $0.207 \mathrm{~V}$, its oxidation is thermodynamically favoured at standard operating conditions of PEMFCs [32]. However, the corrosion rate of carbon is generally very low at voltages below $0.9 \mathrm{~V}$ and at typical operating temperatures of $60-90{ }^{\circ} \mathrm{C}$, but it accelerates at voltages higher than $1.1 \mathrm{~V}$ [33].

Local regions at high overpotentials at the cathode side appear as a result of partial flooding in the corresponding opposite parts at the anode side. As a consequence, more oxygen is permeating 
through the membrane, causing anode potential increase to ca. $0.59 \mathrm{~V}$ [34]. This happens especially during fast dynamic and start-up operating conditions, where the power load changes faster than the gas transport in the electrode. Then, the voltage must temporarily shift to higher values to keep the potential difference imposed by the active part of the cell while still supplying current. This can raise the cathode potential to $1.5 \mathrm{~V}$, dramatically accelerating the rate of carbon corrosion in the cathode catalyst layer.

Carbon corrosion leads to further decrement of the ECSA as well as to a thinning of the catalyst layer, as Pt nanoparticles may lose their support agglomerating to larger particles or detach and be lost. Additionally, the electronic resistance increases due to Pt particle disconnection from the electrical network caused by a loss of carbon support.

\subsection{Performance Losses and Degradation Mechanisms Associated to Drying Out}

A scarce humidification of the membrane electrode assembly (MEA) causes low proton conductivity in Nafion which leads to an increment of ohmic resistances in the membrane and in the ionomeric phase of the catalyst layer. A drying out of the ionomer in the calyst layer can also cause an increment of kinetic overpotential especially on the anode side [35].

Long cell exposure under dehydrated conditions enhances the chemical degradation of the Nafion membrane. This is mainly due to the fact that common impurities present in the reactants, as for example sulfate and ferrous ions, which accumulate under these conditions while they are washed out in drain water at a higher relative humidity. Some of these species act as catalysts for the membrane decomposition reactions promoted by the $\mathrm{H}_{2} \mathrm{O}_{2}$ which is produced as a by-product in the fuel cell $[36,37]$.

Nafion is susceptible to peroxide and radicals, as they attack the end groups of the polymeric membrane with residual hydrogen, initiating decomposition chain reactions. As an example, carboxylic groups are attacked by hydroxy radicals according to [37]:

$$
\begin{aligned}
\mathrm{R}-\mathrm{CF}_{2} \mathrm{COOH}+\bullet \mathrm{OH} & \rightarrow \mathrm{R}_{\mathrm{C}} \mathrm{F}_{2} \bullet+\mathrm{CO}_{2}+\mathrm{H}_{2} \mathrm{O} \\
\mathrm{R}_{\mathrm{C}} \mathrm{F}_{2} \bullet+\bullet \mathrm{OH} & \rightarrow \mathrm{R}-\mathrm{CF}_{2} \mathrm{OH} \rightarrow \mathrm{R}-\mathrm{COF}+\mathrm{HF} \\
\mathrm{R}-\mathrm{COF}+\mathrm{H}_{2} \mathrm{O} & \rightarrow \mathrm{R}-\mathrm{COOH}+\mathrm{HF} .
\end{aligned}
$$

This mechanism of degradation results in membrane thinning and a consequent lowering of mechanical strength. Therefore, phenomena like creeping in tension points of the membrane and pinholes formation accelerate leading to the abrupt increase of gas crossover and finally to cell failure.

\subsection{Performance Losses and Degradation Mechanisms Associated to Starvation of Reactants}

Reactant starvation due to external factors can be caused by a malfunction of the oxidant and fuel conditioning system. This specific source of starvation must be identified and distinguished from the flooding, since the corrective action to decrease its consequences involves an adjustment of different operating parameters like flow rates.

Failures of the reactant supply unit can lead to insufficient oxidant and/or fuel flows, and a scarce humidification of the membrane. The diminution of the reactant flow rates leads to the accumulation of produced water and formation of flooding areas mainly near the gas inlet [38]. Therefore, the acceleration of the same degradation mechanisms described in the Section 2.1 occurs in these electrode regions. Additionally, the oxidant flow rate influences the dynamic behaviour of the cell, increasing the voltage undershoot during the load change of power. On the anode side, severe carbon corrosion has been observed during long operating times in fuel starvation conditions [28,39]. Defects in the humidity supply system result in membrane dehydration favouring the previously discussed membrane degradation mechanisms. 


\subsection{Performance Losses and Degradation Mechanisms Associated to Impurities}

Different impurities often present in small traces in the air and hydrogen streams affect the fuel cell performance through different mechanisms. Some of them may adsorb on the catalyst surface of the anode and cathode decreasing available catalytic sites for the ORR and hydrogen oxidation reaction (HOR) reactions, causing kinetic overpotential losses. One example is carbon monoxide, which is often present in hydrogen streams produced via steam reforming and is the most common anode catalyst poison. CO adsorbs on the Pt forming a strong bond with the metal. An even concentration of a few ppm can dramatically lower cell performance. However, long exposure to $\mathrm{CO}$ poisoning does not affect the durability of the cell and performance losses appear to be completely recoverable by different methodologies like, for example, air bleeding [40].

Another common impurity present in traces in the fuel obtained by the reforming of natural gas is hydrogen sulphide. As in the case of $\mathrm{CO}$, this compound has a strong affinity to metals like platinum and can adsorb on catalytic sites leading to similar degradation consequences [41]. Similar to CO, performance losses are recoverable via electrochemical oxidation of the adsorbed species at potentials between $0.8-1.3 \mathrm{~V}$.

The cathode side is generally exposed to air pollutants, which succeeded to pass the filter located before the cell inlet in the PEMFCs systems. A very common pollutant in urban areas and in proximity of some chemical plants is the sulfure dioxide produced from fossil fuel combustion. The adsorbed $\mathrm{SO}_{2}$ on the catalyst surface can be oxidatively removed by performing cyclic voltammetry.

Some impurities form cations that can exchange with protons of the sulphonic groups of the Nafion membrane. This substitution lowers the proton conductivity and consequently increases the ohmic losses. A common impurity acting in this way is ammonia, which is often contained in fuel streams coming from natural gas reforming. Basically, $\mathrm{NH}_{3}$ reacts with ionomeric $\mathrm{H}^{+}$on the sulfonic groups of the membrane forming $\mathrm{NH}_{4}{ }^{+}$. The poisoning process starts on the anode catalyst layer and continues into the membrane as the ammonia diffuses [42]. Short-term exposure to $\mathrm{NH}_{3}$ (below $1 \mathrm{~h}$ ) shows reversible effects on performance. On the contrary, it has been shown that long term exposure leads to irreversible degradation and an incomplete recovery of cell performance. Salts like $\mathrm{NaCl}$ coming from sea mists can contaminate the air cathode supply poisoning the membrane through an exchange of protons with $\mathrm{Na}^{+}$. A large quantity of salts also decrease the hydrophobicity of the gas diffusion layer (GDL) incrementing the retention time of water and subsequently the mass transport resistance of oxygen.

\section{FRA Methodologies Applied to PEMFCs}

As shown in the previous section, a PEMFC is a complex system involving many processes occurring in parallel, which influence the performance to a different extent depending on operating conditions. With this respect, different FRA methodologies were applied so far in order to separate the contributions of these phenomena to the performance. These studies were performed with two main purposes: Diagnosis and performance optimisation. This section reviews all of them, starting from the description of a common linear FRA theoretical framework.

\subsection{Theoretical Background}

The theoretical backgrounds of FRA techniques involving electrical and nonelectrical quantities to study the dynamics of electrochemical systems have been extensively studied in the past. For example, a general mathematical framework to formulate and analyse different transfer functions has been proposed by Gabrielli and Tribollet [43]. A methodology to assess the reliability of the data collected through frequency response experiments on general electrochemical systems has been illustrated by Macdonald [44]. Recently, Collet-Lacoste [45] performed an analysis of the relationship between a generic perturbation and a certain response in electrochemical systems based on the non-equilibrium thermodynamic theory. 
As one of the main purposes of FRA techniques is the decoupling of a certain contribution from the others, it is important to clarify a mathematical structure that allows one to quantify information contained in a certain transfer function regarding specific dynamics in relation to the input/output configuration considered. A framework for this analysis was introduced in our previous publication (Sorrentino et al. [16]) in order to estimate the capability of an FRA technique based on different concentration inputs to detect specific dynamics. An extended version of this framework is described in the following.

According to the LST, any set of equations describing the dynamic behaviour of a lumped or distributed time invariant system can be reduced or approximated to the following mathematical form $[46,47]$ :

$$
\begin{aligned}
& \dot{X}=F(X, W) \\
& Y=G(X, W) .
\end{aligned}
$$

The elements $x_{i}$ of the vector $X$ represent the state variables, the values of which describe the state of the system, while the components $w_{j}$ of the vector $W$ are the input quantities or constraints that are imposed by the experimental conditions. Furthermore, the input quantities $y_{k}$ of $Y$ represent the output variables that allow the state of the system to be observed. Generally, the set functions $F_{i}$ and $G_{k}$ are nonlinear as most of the physical systems are. In case of the distributed system, the partial differential equations constituting it are discretised by a system of ordinary differential equations through numerical discretisation methodologies.

In the context of electrochemical systems, the elements of such vectors could be defined as: (i) $x_{i}$ could be, for example, the concentration of the reactants in the gas stream or of the species in the electrolyte, coverage fraction of intermediate species on the electrode surface, or the local overpotential; (ii) $w_{j}$ can be the overall voltage or current, temperature, partial or total pressure, etc.; and (iii) as $y_{k}$ the voltage and current can be measured, as well as the reflective power of a photosensitive electrode surfaces, the mass added or removed due to adsorption/desorption of intermediate species and the reactant concentrations coming out from the system. The nonlinearities of the functions $F_{i}$ and $G_{k}$ are mostly attributable to the exponential activation of the electrochemical reaction rates by the potential.

Considering the solution of the system at a fixed steady state, the dynamic response to a certain small input perturbation can be calculated through the linearisation of the equation system with respect to the steady state value of the state and input variables. The following simplified version fo the system is obtained:

$$
\begin{aligned}
& \dot{X}=A X+B W \\
& Y=C X+D W
\end{aligned}
$$

where $A-D$ respectively represent the so called state space, controllability, observability, and transmission matrixes, the components of which are equal to:

$$
A_{i, j}=\left.\frac{\partial F_{i}}{\partial x_{j}}\right|_{x_{k}, w_{m}, k \neq j} B_{i, j}=\left.\frac{\partial F_{i}}{\partial w_{j}}\right|_{x_{k}, w_{m}, m \neq j} C_{i, j}=\left.\frac{\partial G_{i}}{\partial x_{j}}\right|_{x_{k}, w_{m}, k \neq j} D_{i, j}=\left.\frac{\partial G_{i}}{\partial w_{j}}\right|_{x_{k}, w_{m}, m \neq j}
$$

Then, it is remarkable that the values of the elements of the matrix $A$ depends on the intrinsic dynamic features of the system, while, in the case of $B$ and $C$, they are respectively functions of the kind of input and output considered. 
Generally, the system response to a perturbation is described through the corresponding transfer function $H(i \omega)$ in frequency domain, obtained by applying the Fourier transform to the system of Equations (11) and (12). It reads:

$$
H(i \omega)=\frac{\tilde{Y}(i \omega)}{\tilde{W}(i \omega)}=C\left(i \omega I_{n}-A\right)^{-1} B+D
$$

For $\Lambda=\operatorname{diag}\left(\lambda_{i}\right) \quad(i=1,2 \ldots n)$ being the diagonal matrix of the eigenvalues $\lambda_{i}$ of $A, P$ the matrix of the corresponding left eigenvectors $p_{i}$, and $Q^{T}=P^{-1}$ the matrix of the corresponding right eigenvector $q_{i}^{T}$, the equivalent canonical form of the system Equations (11) and (12) reads [46,48]:

$$
\begin{aligned}
\dot{X}_{d} & =\Lambda X_{d}+Q^{T} B W=X_{d}+\beta W \\
Y & =C P X_{d}+D W=\gamma X_{d}+D W
\end{aligned}
$$

where $\beta=Q^{T} B$ constitutes the normal form of the input matrix, while $\gamma=C P$ is the normal output matrix. According to this new representation, the transfer function expressed in the Equation (14) for a single input single output (SISO) system can also be written in the following simplified form:

$$
H(i \omega)=C P\left(i \omega I_{n}-\Lambda\right)^{-1} Q^{T} B+D=\sum_{k=1}^{n} \frac{r_{k}}{i \omega-\lambda_{k}}+d_{1}
$$

where

$$
r_{k}=C p_{k} q_{k}^{T} B=\sum_{i=1}^{n} \sum_{j=1}^{n} c_{1, i} p_{i, k} q_{k, j}^{T} b_{j, 1}=\gamma_{1, k} \beta_{k, 1}
$$

The quantities $r_{k}$ represent the elements of the residual vector, each one relative to a certain dynamic state variable $k$ characterised by a time constant $\tau_{k}=-\frac{1}{\lambda_{k}}$. As displayed, they are dependent on the product of the $k$ elements of the normal form of the input and output vectors, which determine the contribution of the corresponding state variable $k$ in the transfer function in a certain input/output system description. If the value of one of the elements of $\gamma$ is zero or negligible compared to the other ones, it means that the dynamics corresponding to the $k$ variable is not observable or does not have a significant contribution to the transfer function based on the considered output. In the same way, if one of the elements of $\beta$ is negligible relative to the others or zero, the corresponding $k$ variable is not controllable and has no influence on the transfer function determined using the related input. Therefore, given a model describing a certain system, the determination of the residual matrix is a valuable theoretical tool to estimate which kind of dynamics influence the most the frequency response spectra using a certain input/output configuration through a comparison of the value of the different matrix elements. Additionally, it can be used for model reduction purposes, suggesting which variable and/or phenomena can be neglected in describing the dynamic effects of a certain perturbation.

A certain degree of controllability and observability of a fixed dynamic variable in the transfer function is not the only condition to be fulfilled for the identification of a process. A sufficient sensitivity of the frequency response function to the changes of parameters influencing the studied phenomena must also be verified. In general, a high sensitivity implies a smaller variance in the measure of a certain parameter, resulting in a more accurate estimation. Given the vector of the parameters $n_{p} \theta=\left(\theta_{1}, \ldots \theta_{n_{p}}\right)$ which characterise the dynamics of a system, the transfer function sensitivity as function of the frequency is computed by the following equation:

$$
\frac{\partial H(i \omega)}{\partial \theta_{m}}=\sum_{k=1}^{n}\left(\frac{\frac{\partial r_{k}}{\partial \theta_{m}}\left(i \omega-\lambda_{k}\right)+r_{k} \frac{\partial \lambda_{k}}{\partial \theta_{m}}}{\left(i \omega-\lambda_{k}\right)^{2}}\right) .
$$


The values of the residual vectors and their derivatives with respect to the fixed parameter determine the part of the sensitivity related to the input/output configuration used. This can be better observed by expressing the derivative of the residual vectors with respect to a generic parameter $\theta_{m}$ :

$$
\frac{\partial r_{k}}{\partial \theta_{m}}=\sum_{i=1}^{n} \sum_{j=1}^{n} c_{1, i} b_{j, 1} \frac{\partial p_{i, k} q_{k, j}^{T}}{\partial \theta_{m}}+p_{i, k} q_{k, j}^{T} \frac{\partial c_{1, i} b_{j, 1}}{\partial \theta_{m}} .
$$

It is noticeable from the Equation (20) that the sensitivity of the residuals not only depends on the value of the elements of the controllability and observability matrix, but also on their sensitivity to the parameter $\theta_{m}$. Then, the Equation (20) can be used to determine which types of input/output configuration and which frequency band are the most suitable for the identification of a class of parameters related to a specific dynamic process.

\subsection{EIS: Use and Limitations of the Most Used FRA Method in Fuel Cell Science}

In EIS, the cell is excited by an electric input (current or voltage) and the complementary electric output is measured. EIS is mainly employed to investigate the influence of different material components and cell designs on fuel cell performance as well as to develop on a board diagnostic tool. In the first case, EIS is applied on different PEMFCs where certain features of the cell are systematically varied. The outcome of the implemented modifications is evaluated through a parameter fitting of a PEMFC model to the EIS spectra. Three different model approaches are usually employed: (i) Physically based, (ii) equivalent circuits (EC), and (iii) data driven models. An example of this operating mode for testing MEA with different electrolyte compositions is displayed in Figure 2.

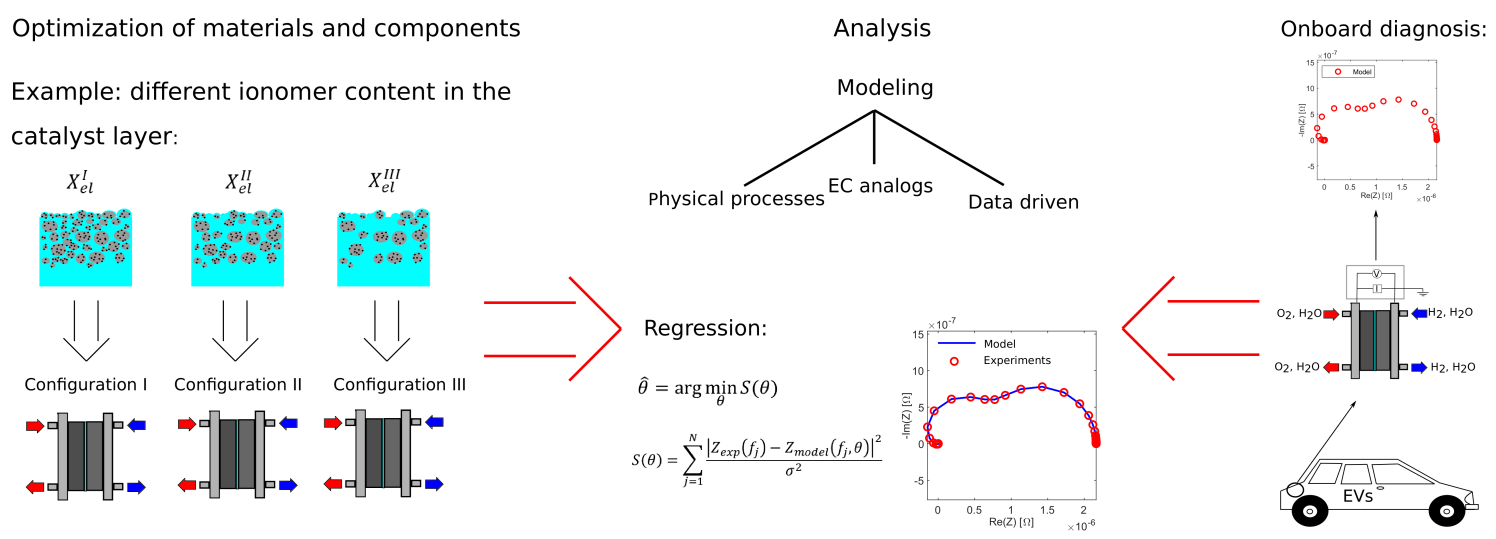

Figure 2. Schematic of the different uses of electrochemical impedance spectroscopy (EIS) or a generic frequency response analysis (FRA) technique discussed in this paper.

Following this general strategy, many characteristics of fuel cells have been improved. For example, a combination of experiments and simulation was used by several groups to investigate the effect of different flow field geometries in order to reduce the mass transport resistance on the cathode side $[49,50]$. Others have focused on the understanding of the relationship between the GDL features and resistance to oxygen transport [51], water removal [52], electron conduction, and heat transport [53] using EIS in combination with other experimental techniques. Moreover, the employment of EIS for a better comprehension of the relationship between catalyst layer structure, its efficiency, and durability was extensive and supported the synthesis of MEA with optimised ionomer content, ionomer/carbon ratio, and platinum loading [54-56]. Finally, the performance of membranes alternative to Nafion were also tested, for example poly-vinylidene-fluoride (PVDF) and polybenzimidazole $[57,58]$.

The implementation of EIS-based real-time monitoring systems for faulty states identification was performed through two different strategies. In the first one, the model runs in parallel with the 
physical system so that the differences between the model and collected impedance spectra in different frequency regions, so called residuals, are measured in real time. If one or more residuals correlated to a certain faulty condition overcome a fixed threshold, a symptom is detected and communicated to the control system which implements a proper fault isolation procedure. On the other side, if the model contains parameters related to the behaviour of a specific component or physical phenomena, a correlation between nominal values of parameters obtained in no faulty conditions can be analysed. Then, the data can be fitted during an operation of the system and when the variation of a parameter achieves a certain limit, the correlated fault can be detected and isolated.

The most used model approach in PEMFCs impedance-based diagnostic tools is the EC approach. The main advantage of this type of model is the simplicity and versatility to describe a wide range of operating conditions and the low computational cost. Several onboard monitoring techniques based on fitting impedance through EC models have been proposed in the last few years. A comprehensive review on the topic was recently published by Petrone et al. [59]. However, EC models have been highly criticised because of their lack of physical interpretation which can lead to misleading conclusions [60].

Only in the last few years have physical-based models been employed in real-time monitoring diagnostic tools giving more trustworthy estimation of parameters in an acceptable time range for on-board applications [61]. One of the few example is presented in the work by Chevalier et al. [62] who found a good compromise between computational costs and model complexity. However, their model did not include important phenomena, for example two phase flows in electrodes. For this reason the fidelity of their model based analysis was limited to a restricted operating parameter range. An interesting approach recently proposed by Goshtabi et al. [63] could allow one to expand the complexity of the models used at a low computational cost. They implemented a computational scheme based on the use of disparate time and length scale for each transient phenomena, which enables one to perform a dynamic simulation of a more complex PEMFC model in a time one order of magnitude faster than the ordinary cases. Even though dynamic voltage step experiments were successfully simulated, the capability of this approach to compute EIS spectra has not been tested yet.

The main problem of the impedance is related to the fact that when using an electrical input and output almost all kind of processes occurring in a fuel cell can be stimulated and detected. In the analysis of complex systems like PEMFCs, this can lead to coupling in the EIS spectra of contributions of several physical processes having similar time constants and the influence of a large amount of structural and operating parameters. For this reason, the analysis of the EIS spectra can lead to a misleading conclusion due to high correlation between the estimated parameters. It should be mentioned that this problem is intrinsic and independent on a model approach implemented for EIS analysis. According to the mathematical framework presented in Section 3.1, this means that the transfer function is characterised by a comparable value of all residuals.

Several patterns have been reported in the PEMFC EIS spectra depending on the operating conditions and dominating processes. The main ones observed in the Nyquist plot representation of the impedance are listed in Table 1. It is noticeable that different conditions can govern the same patterns contributing to difficulties in the diagnosis. As already discussed, due to the several processes occurring in the cell, the interpretation of many patterns observed is still under debate in the scientific community.

Using well humidified pure oxygen feeds, one arc is obtained in the Nyquist plot which is localised in a high frequency region ( $\mathrm{f}>10 \mathrm{~Hz}$ ), as the one depicted in the first row of Table 1. This loop is related to the double layer capacitance of the electrode combined with the charge transfer of the ORR reaction. The diameter of the arc is a measure of the charge transfer resistance and its magnitude decreases going to a lower potential, as the reaction rate increases [64]. Generally, this capacitive arc is mainly used as an indicator of catalyst properties such as catalyst surface area, catalyst loading, and catalyst utilization [54-56,65]. 
Table 1. Most common pattern of EIS Nyquist plot related to polymer electrolyte membrane fuel cells (PEMFCs). The figures are respectively adapted from Springer et al. [64], Paganin et al. [66], Ciurenau et al. [67], and Wiezell et al. [68].

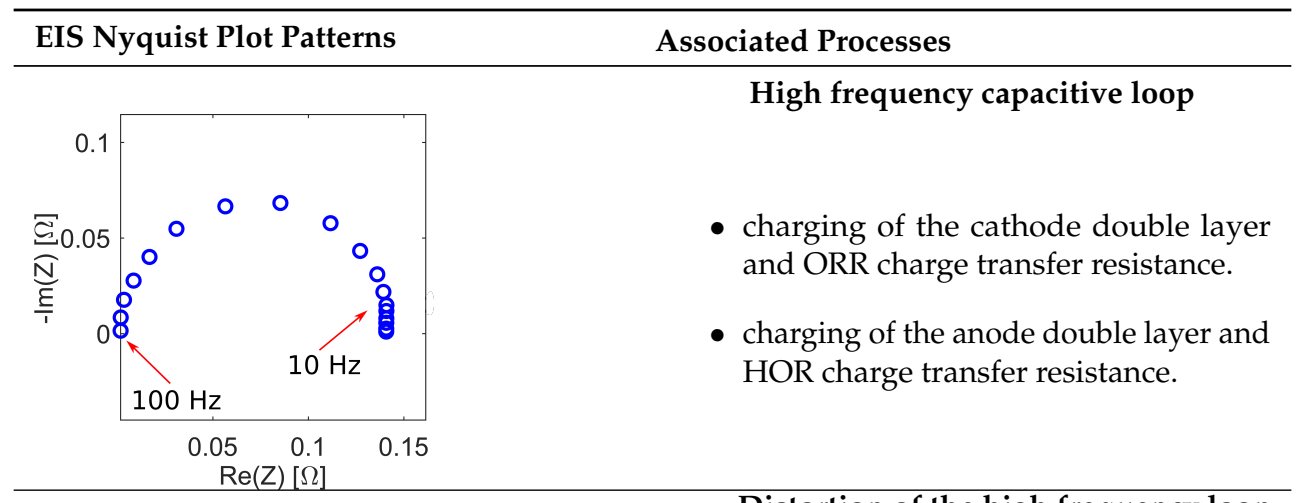

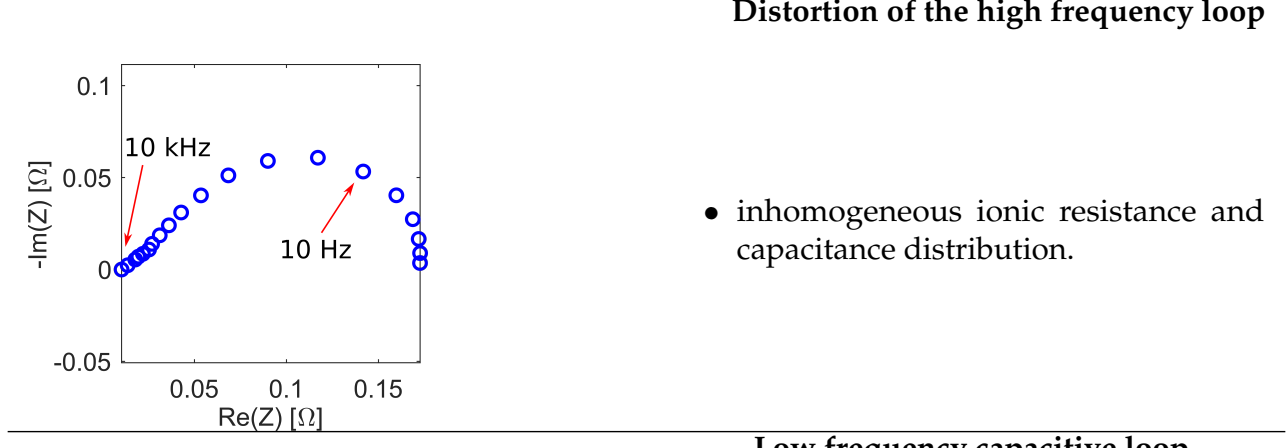

Distortion of the high frequency loop

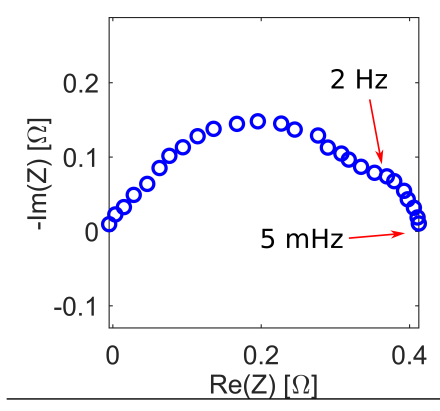

Low frequency capacitive loop

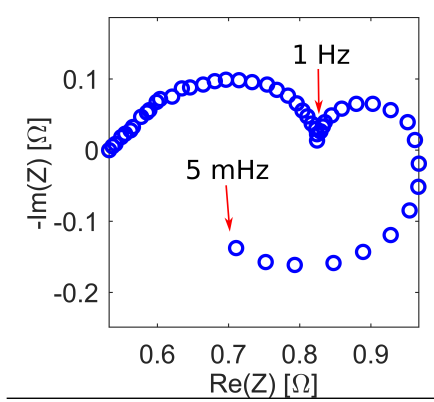

- mass transport of oxygen along the cathode flow field channel.

- dehydration of ionomers of the anode catalyst layer.

Low frequency inductive loop

- adsorption steps of the ORR and/or platinum oxidation and dissolution.

- CO poisoning on the anode catalyst.

- hydration of the Nafion membrane through back diffusion of water.

The value of the high frequency intercept with real axes represents the total ohmic resistance of the cell which can be expressed as the sum of the ohmic resistances of the cell components such as membrane, catalyst layer, GDL, and bipolar plates, and of the contact resistances between them $[69,70]$. The determination of these features has been extensively used as an indicator of the hydration state of the membrane and for the optimisation of the humidity level of PEMFCs in order to avoid drying out $[71,72]$. Furthermore, high frequency intercept monitoring has been employed to evaluate the 
dependence of the contact resistance of the GDL and catalyst layer along with the cell compression, and to detect poisoning due to traces of $\mathrm{NH}_{3}$ in the anode feed [73-75].

A distortion of the semicircle at high frequencies represented by a straight line of $45^{\circ}$ with respect to the real axis can be often observed in a condition of low humidity, as displayed in the second row of Table 1. This distortion can be accompanied by a smaller potential independent loop partially overlapped with the larger one. The behaviour of this pattern has been extensively studied and interpreted through the development of different physical model approaches such as pore models, agglomerate models, macro-homogeneous models, and flooded agglomerate models as well as EC [64,66,76-79]. It was found to be related to the coupling effect of the distributed ionic resistance and distributed capacitance in the catalyst layer which is emphasised under conditions of limited protonic conductivity. The fitting of this distorted arc was used to determine parameters related to the structure of the catalyst layer like the electric conductivity of the carbon phase, protonic conductivity of the ionomer, and catalyst utilisation. In order to improve the quality of parameter estimation obtained by the fitting of this pattern of EIS spectra, the impedance experiments were performed on cell operating with $\mathrm{H}_{2} / \mathrm{N}_{2}$ gas feed configuration. In this way, the contribution of the ORR and mass transport effects in the spectra can be avoided $[77,79]$.

The contribution of the anode charge transfer on the high frequency capacitive loop is usually considered negligible. However, many studies on PEMFCs with symmetrical $\mathrm{H}_{2} / \mathrm{H}_{2}$ configurations have shown that under conditions of considerable mass transport resistance on the anode side, the starvation of hydrogen at the catalyst interface increases the overpotential and size of the related high frequency arc [80,81]. Additionally, the contribution of the anode charge transfer resistance becomes significant at low humidity conditions and/or if using thicker membranes. The phenomena has been explained with the scarce hydration of the ionomer in the anode catalyst layer [35].

When EIS is performed on fuel cells operating in $\mathrm{H}_{2}$ /air instead of $\mathrm{H}_{2} / \mathrm{O}_{2}$ configuration an additional capacitive loop appears in the Nyquist plot at frequencies below $10 \mathrm{~Hz}$. An example is shown in the third row of Table 1 . The size of this additional arc increase with the overpotential and often overlaps completely with the charge transfer contributions at a higher frequency $[64,67,82,83]$. This pattern was initially attributed to mass transport resistance in the GDL and catalyst layer. New findings have shown that this feature is related to the dynamics of the mass transport and reactant depletion along the flow field channels. As first observed by Schneider et al. [84-86], oxygen concentration oscillations build up along the cathode gas channel during EIS experiments in the frequency range between 10 and $0.01 \mathrm{~Hz}$, causing an additional polarisation sinusoidal voltage contribution in the downstream part of the flow field which couples to the modulated voltage at the electrode imposed by the electric control. The local interaction between these two periodic voltage variations evoke the formation of positive and negative resistance loops along the channel due to an additive and subtractive concentration polarisation contribution respectively. This determines the characteristics of the impedance arc at low frequencies.

Many physically-based or EC models have been developed in order to fit the low frequency impedance features and to evaluate transport parameters as for example oxygen diffusivity and internal flow rate velocity to diagnose flooding states [87-91].

A capacitive loop has also been observed in the same frequency region using pure oxygen as a cathode feed under low humidity conditions which cannot be attributed to oxygen depletion dynamics along the channel $[68,92,93]$. Instead, it has been related with a large acceptance to characteristics of water transport in the membrane and ionomer in the anode catalyst layer. Due to the effect of the electrosmotic flux, a temporary drying out of the ionomer in the anode catalyst layer occurs during EIS experiments at low frequencies. This phenomena leads to a higher charge transfer resistance and results in the appearance of a capacitive loop in the Nyquist plot. It has been shown that the use of air masks completely the capacitive arc due to the dehydration in the Nyquist plot, making impossible to diagnose the drying out of the anode under such conditions $[68,93]$. 
Finally, an inductive loop crossing on the positive side of the imaginary axis has been observed in the impedance Nyquist plot of PEMFCs under different operating conditions at frequencies below $0.1 \mathrm{~Hz}$ (see the figure in the last row of the Table 1). The explanation of this inductive behaviour has been the object of debate in the scientific community for many years [3].

Many authors have suggested that the inductive loop could be attributed to the effect of the side reactions occurring in the cell. These reactions include several potential and non potential-dependent steps with adsorbed intermediate species, some of them related to the degradation of membrane and electrodes. Several studies proposed that the relaxation of some adsorbed intermediates participating in the ORR could originate such a pattern [94-96]. Some other works stated that platinum oxide formation and dissolution occurring in parallel with the ORR could also generate an inductive loop [95-98].

A strong pseudo inductive behaviour was also detected below $3 \mathrm{~Hz}$ under condition of $\mathrm{CO}$ poisoning of the anode catalyst [99]. This path was attributed to a surface relaxation process due to the competitive oxidation of hydrogen and carbon monoxide at the anode. The progressive increment of the size of the pseudo inductive loop with the time makes the $\mathrm{CO}$ poisoning recognisable from other processes causing inductive patterns.

Another explanation that has been given for the inductive loop is related to the slow dynamics of water uptake in the Nafion membrane $[68,81,93]$. Basically, it has been proposed that the AC current applied during the EIS measurements perturbs the hydration state of the membrane at lower frequencies changing the production of water at the cathode. The water generated can be transported by gradient forces to the anode increasing the water content of the membrane. As a final result, a decrement of the resistance of the cell is obtained which is expressed by an inductive loop in the Nyquist plot [100,101].

A recent work of Setzler and Fuller [102] hypothesised that both water build up and platinum oxide growth could generate inductive loops, but one of them can prevail depending on experimental conditions. According to these authors, at a high steady state current density, the variation of the current generates an increment of temperature that offsets the effect of the water generation. Under these circumstances, the inductive loop is dependent on the relaxation due to platinum oxide formation kinetics.

\subsection{Frequency Response Methodologies Based on Nonelectrical Quantities}

The ambiguities in the attribution of the patterns observed in the EIS spectra of PEMFCs have driven the research on novel methods to decouple these underlying contributions. An approach to achieve this purpose is the development of FRA techniques alternative to EIS based on nonelectrical inputs and/or outputs. As suggested by the LST in Section 3.1, the stimulation or detection of a different physical variable could only trigger and give feedback information about specific dynamics, making possible to decouple and identify selected contributions from others. Following this idea, the perturbation of different variables was used to excite PEMFC or a selected observable was monitored in order to measure the contribution on the performance of a targeted process. In Table 2, all combinations of inputs and outputs used in the FRA techniques applied to PEMFCs updated to the date of submission of this report are displayed. The acronyms of the FRA techniques, which are introduced in the next section, are indicated in the box matching the relative input/output configuration. The blank boxes indicate the configuration still not contemplated in any FRA method. It is noticeable that almost all the techniques proposed involve an electrical quantity as input or output, while only one technique involves only nonelectrical quantities. 
Table 2. An overview of input/output combinations applied in PEMFC research and corresponding frequency response functions.

\begin{tabular}{|c|c|c|c|c|c|c|c|c|}
\hline 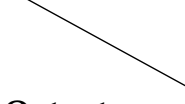 & $I$ & V & $P_{\text {out }}$ & $P_{\mathrm{O}_{2}}$ & $P_{\mathrm{H}_{2} \mathrm{O}}$ & $T_{\text {cell }}$ & $T_{\text {sur }}$ & $t_{\mathrm{H}_{2} \mathrm{O}}$ \\
\hline$I$ & $X$ & EIS & EPIS & $\operatorname{cFRA}\left(\mathrm{O}_{2}\right)$ & $\mathrm{cFRA}\left(\mathrm{H}_{2} \mathrm{O}\right)$ & & & \\
\hline V & EIS & $X$ & EPIS & $\mathrm{cFRA}\left(\mathrm{O}_{2}\right)$ & $\mathrm{cFRA}\left(\mathrm{H}_{2} \mathrm{O}\right)$ & & & \\
\hline$P_{\text {out }}$ & EPIS & EPIS & $X$ & & & & & \\
\hline$P_{\mathrm{O}_{2}}$ & & & & $X$ & & & & \\
\hline$P_{\mathrm{H}_{2} \mathrm{O}}$ & & & & & $X$ & & & \\
\hline$T_{\text {cell }}$ & & & & & & $X$ & & \\
\hline$T_{\text {sur }}$ & ETIS & & & & & LIT & $X$ & \\
\hline$t_{\mathrm{H}_{2} \mathrm{O}}$ & HECII & & & & & & & $X$ \\
\hline
\end{tabular}

While for the PEMFCs field this is a relatively new approach, many nonelectrical FRA techniques have been introduced for the study of different electrochemical systems in the last 50 years, giving a significant contribution. Two of the most notable examples are the AC-electrogravimetry and the electrohydrodynamical impedance (EHD) which respectively involve the mass variation of the electrode as output and the angular velocity of the rotating disk electrode as input. AC electrogravimetry gave significant contribution to elucidate the mechanism of ion transport in electroactive films $[103,104]$, while EHD was mostly employed for studying the influence of surface films forming on the electrodes [105].

The interest in the development of FRA methodologies based on nonelectrical quantities for the study of PEMFCs has attracted the interest of the scientific community only in the last decade. This is probably due to the technical difficulties in perturbing and measuring at a high sampling rate other variables aside from electrical ones in an electrochemical system. Additionally, the convenience of using well-established protocols and hardware have pushed research to overcome the limitation of EIS through a different approach of data analysis rather than in the advancement of other dynamic diagnostic tools. Differently from Table 2, Table 3 reports a list of the mathematical expression of the transfer functions of the nonelectrical FRA proposed in the last years mentioning the detected processes by each of them. 
Table 3. A summary of transfer functions based on nonelectrical input or output and main processes isolated by these methods.

\begin{tabular}{|c|c|c|}
\hline FRA Technique & Transfer Function & Processes Isolated \\
\hline \multirow{4}{*}{ EPIS } & $Z_{V / P}=\frac{\Delta \tilde{V}(i \omega)}{\Delta \tilde{P}(i \omega)}$ & \multirow{4}{*}{$\begin{array}{l}\text { Mass transport gaseous reactants and liquid } \\
\text { water in the channel, GDL and catalyst layer }\end{array}$} \\
\hline & $Z_{I / P}=\frac{\Delta \tilde{I}(i \omega)}{\Delta \tilde{P}(i \omega)}$ & \\
\hline & $Z_{P / V}=\frac{\Delta \tilde{P}(i \omega)}{\Delta \tilde{V}(i \omega)}$ & \\
\hline & $Z_{P / I}=\frac{\Delta \tilde{P}(i \omega)}{\Delta \tilde{I}(i \omega)}$ & \\
\hline \multirow{4}{*}{ cFRA } & $\zeta_{\mathrm{O}_{2}}^{I}=\frac{\Delta \tilde{\mathrm{P}}_{\mathrm{O}_{2}}(i \omega)}{\Delta \tilde{V}(i \omega)}$ & Mass transport of oxygen in the channel. \\
\hline & $\zeta_{\mathrm{O}_{2}}^{V}=\frac{\Delta \tilde{P}_{\mathrm{O}_{2}}(i \omega)}{\Delta \tilde{I}(i \omega)}$ & $\begin{array}{l}\text { Gas transport of oxygen in the channel.- } \\
\text { Water sorption in the Nafion membrane. }\end{array}$ \\
\hline & $\zeta_{\mathrm{H}_{2} \mathrm{O}}^{I}=\frac{\Delta \tilde{P}_{\mathrm{H}_{2} \mathrm{O}}(i \omega)}{\Delta \tilde{V}(i \omega)}$ & \multirow[t]{2}{*}{$\begin{array}{l}\text { Water mass transport in the channel. - Water } \\
\text { sorption in Nafion }\end{array}$} \\
\hline & $\zeta_{\mathrm{H}_{2} \mathrm{O}}^{V}=\frac{\Delta \tilde{P}_{\mathrm{H}_{2} \mathrm{O}}(i \omega)}{\Delta \tilde{I}(i \omega)}$ & \\
\hline \multirow{2}{*}{ cFRA (mixed) } & $\zeta_{\mathrm{O}_{2}}^{I, m i x}=\zeta_{\mathrm{O}_{2}}^{I}+\frac{\Delta \tilde{P}_{\mathrm{H}_{2} \mathrm{O}}(i \omega)}{\Delta \tilde{P}_{\mathrm{H}_{2} \mathrm{O}}(i \omega)} \zeta_{\mathrm{H}_{2} \mathrm{O}}^{I}$ & \multirow{2}{*}{$\begin{array}{l}\text { Mass transport gaseous reactants in the } \\
\text { channel. Water sorption into the Nafion } \\
\text { membrane. }\end{array}$} \\
\hline & $\zeta_{\mathrm{O}_{2}}^{V, m i x}=\zeta_{\mathrm{O}_{2}}^{V}+\frac{\Delta \tilde{P}_{\mathrm{H}_{2} \mathrm{O}}(i \omega)}{\Delta \tilde{P}_{\mathrm{H}_{2} \mathrm{O}}(i \omega)} \zeta_{\mathrm{H}_{2} \mathrm{O}}^{V}$ & \\
\hline ETIS & $Z_{E T I S}=\frac{\Delta \tilde{T}(i \omega)}{\Delta \tilde{I}(i \omega)}$ & $\begin{array}{l}\text { Heat transport along the flow fields.-Water } \\
\text { generation. }\end{array}$ \\
\hline LIT & $Z_{L I T}=\frac{\Delta \tilde{T}_{\text {surface }}(i \omega)}{\Delta \tilde{T}_{\text {in }}(i \omega)}$ & $\begin{array}{l}\text { Water accumulation along the flow fields and } \\
\text { GDL. }\end{array}$ \\
\hline HECII & $Z_{H E C I I}=\frac{\Delta \tilde{W}_{k n o w n}(i \omega)}{\Delta \tilde{I}(i \omega)}$ & Water generation. \\
\hline
\end{tabular}

The first nonelectrical perturbation considered by several groups to develop alternative FRA methodology for fuel cells has been the cathode back pressure that has resulted in the establishment of the electrochemical pressure impedance spectroscopy (EPIS). The earliest work in this direction was the one of Niroumand et al. [8] who observed the arise of cathode back pressure autonomous oscillations by using low flow rates inducing as a consequence of voltage sinusoidal waves. As the two periodic perturbations were not in phase, they related this phenomenon to the dynamics of the water accumulation in the cathode catalyst layer and GDL causing simultaneously the increment of the back pressure and diminution of the electrochemical catalyst surface area available for the ORR. This resulted finally in the lowering of the voltage. Based on these findings, they proposed to stimulate the cell through periodically modulated back pressure at a certain low frequency range $(0.1-20 \mathrm{~Hz})$ and to analyse the voltage response. The determined transfer function should be able to isolate contributions of the liquid and gas transport dynamics. Unfortunately, they were not successful to practically realise and demonstrate their idea. However, they developed a robust fault detection and isolation (FDI) algorithm which used the arise of the cathode back pressure and voltage oscillations as 
diagnostic criteria to isolate flooding from cathode and anode starvation [9]. Basically, the monitoring of sustained voltage oscillations which increased by lowering the cathode flow rate was labelled as flooding characteristics, while the sudden increment of the voltage amplitude over a certain threshold was implying cathode starvation. On the other hand, the lowering of the voltage without oscillations was considered a clear indication of anode starvation.

The first application of EPIS was on a sodium/oxygen battery by Hartman et al. [11]. The periodic perturbation was produced via a controlled valve regulating the pressure of the inlet oxygen, while a sensor was collocated immediately after measuring pressure changes. The system was kept under galvanostatic control, so that the voltage response was registered. The determined EPIS spectra were selectively detecting the dynamics of the oxygen transport to the cathode limited by its low solubility in the aqueous electrolyte. The phase angle plot indicated that these diffusion processes dominate the system exhibiting a Warburg-like impedance. The sensitivity analysis performed employing a multi-physic model indicates that the diffusivity of the oxygen, thickness of the double layer and oxygen solubility are the parameters influencing the most of the spectra. In this regard, EPIS was found to be a suitable instrument to investigate the impact of mass transport phenomena.

The detailed theoretical analysis of Gruebl et al. [10] investigated the potential of EPIS to the study of a generic electrochemical cell (i.e., fuel cells, metal air batteries, electrolyzers). Additionally, both current and voltage were considered not only a response, but as input as well, widening the number of possible EPIS transfer functions (please check Table 2 and 3). Using a one-dimensional reaction transport model of a generic cell, they confirmed the ability of EPIS to selectively detect gas transport mechanisms. In this respect, particularly useful were the spectra of the transfer function $Z_{I / P}$ determined by registering the pressure response and current output, as they displayed spiral-shaped features at high frequencies that systematically depend on cell geometry. A more systematic sensitivity analysis based on the determination of the relative sensitivity coefficient of different parameters showed that EPIS spectra are more influenced by processes related to transport and cell geometry, while EIS is more affected by electrode kinetics and double layer capacitance.

The application of EPIS on PEMFCs was performed by Engebretsen et al. [12] and more recently by Shirsath et al. [18]. Both groups only conducted experiments under galvanostatic conditions registering the voltage responses and determining the EPIS transfer function $Z_{V / P}$ (see Table 3). Engebretsen et al. [12] developed a setup capable of generating back-pressure perturbations using a loudspeaker arrangement collocated at the cathode outlet (see Figure 3). Such a system allowed one to achieve input frequencies up to $100 \mathrm{~Hz}$, but it has the disadvantage of producing signals with high noise content. They observed a monotonous increase of EPIS magnitude with an increase of frequency (Figure 3) apparently showing a single dynamics, while the phase (Figure 3c) displayed a decrement until the value of zero at low frequencies indicating that the input and output were in phase and no delay in the response was present. The EPIS magnitude increases with the steady state current density due to the higher mass transport resistance. EPIS spectra registered at different humidity values of the gas inlet show a sensitivity of this technique to this parameter on both anode and cathode sides. 

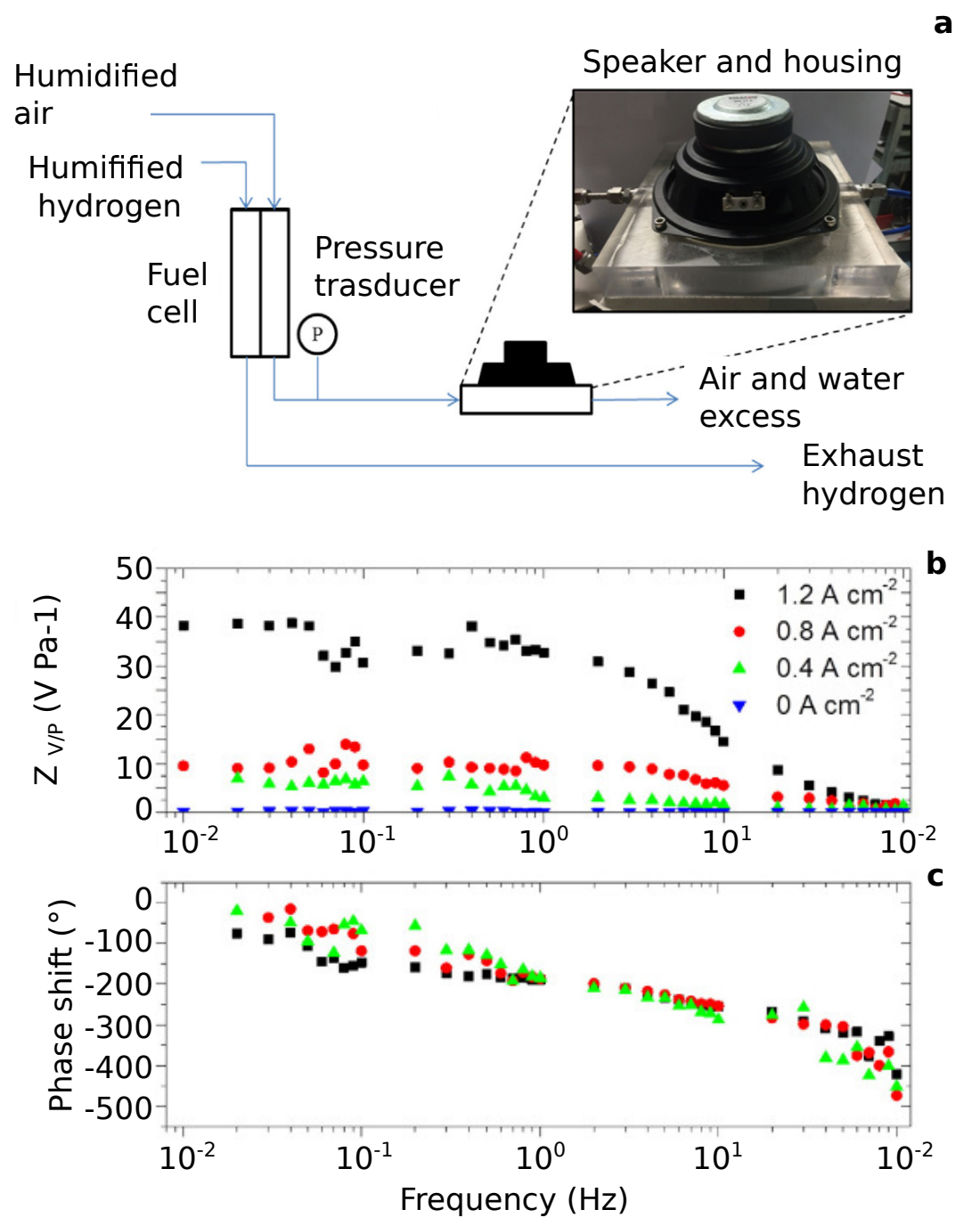

Figure 3. Electrochemical pressure impedance spectroscopy (EPIS) methodology: (a) EPIS setup developed by Engebretsen et al. [12], (b) EPIS magnitude Bode plots at different steady state, and (c) EPIS phase Bode plots at different steady states. Figures adapted from [12].

Shirsath et al. [18] used a setup producing back pressure perturbation through a controlled valve at the outlet. This way, they were able to obtain cleaner spectra, but the frequency range was limited up to $1 \mathrm{~Hz}$. The trends obtained in the EPIS spectra were somehow contrasting to the ones of Engebretsen et al. [12]. The EPIS magnitude decreases at lower frequencies instead of increasing. On the other hand, the phase characteristics in both studies show very good qualitative and quantitative agreement.

A different approach has been proposed by Sorrentino et al. $[16,17,106]$ who developed a FRA methodology named concentration-alternating FRA (cFRA) based on the stimulation of the cathode of a PEMFC through a feed characterised by a periodic concentration of a certain component of the gas mixture. Basically, oxygen and water concentrations were used as inputs, while the electric response was current or voltage depending on the control applied to the cell, i.e., voltastatic or galvanostatic. Considering all the combinations of inputs and outputs, four cFRA transfer function could be determined which are expressed in Table 2 and 3. In the first theoretical study [16], the simulations obtained using a one-dimensional PEMFCs model showed that the dynamics of oxygen transport in the channel could be selectively observed in the spectra of the cFRA oxygen transfer function under galvanostatic conditions $\zeta_{\mathrm{O}_{2}}^{I}$. On the other hand, by using water input (transfer functions $\zeta_{\mathrm{H}_{2} \mathrm{O}}^{I}$ and $\zeta_{\mathrm{H}_{2} \mathrm{O}}^{V}$ ), only the dynamics of water absorption was detected. Moreover, the same spiral patterns observed in the work of Hartman et al. [11] were seen in the Nyquist plot and found to be related to 
the delay between the input and output due to the gas transport from the channel and gas diffusion layer to the electrode. It was found that the time constant of these processes could be directly estimated through this feature. Finally, a sensitivity analysis demonstrated that cFRA had a higher sensitivity to kinetic and transport parameters than EIS.

The finding of the theoretical studies on cFRA were partially validated. For this, a setup capable of producing a cathode feed with simultaneous periodic variation of oxygen and water concentrations was developed $[17,106]$.The schematic of the setup is illustrated in Figure 4a. Due to the impossibility of decoupling simultaneous inputs, the measured cFRA transfer functions $\zeta_{\mathrm{O}_{2}}^{I, \text { mix }}$ and $\zeta_{\mathrm{O}_{2}}^{V, \text { mix }}$ were linear combinations of the single ones related to the two concentration inputs, as reported in Table 3 . Nevertheless, it is noticeable from the spectra in Figure $4 \mathrm{~b}$ that these mixed transfer functions were only affected by transport phenomena related to oxygen and water as the magnitude converge to zero at higher frequencies. This confirmed the ability of the cFRA to decouple these contributions from dynamics of electrical phenomena at electrode interface, as for example the charging of the double layer. Additionally, the spectra collected at different humidity of the feeds presented a different qualitative shape depending if the anode or the cathode were in dried conditions (see Figure 4c). The author proposed that this behaviour could be used to diagnose defects in the functioning of the humidification system of cell hardware.
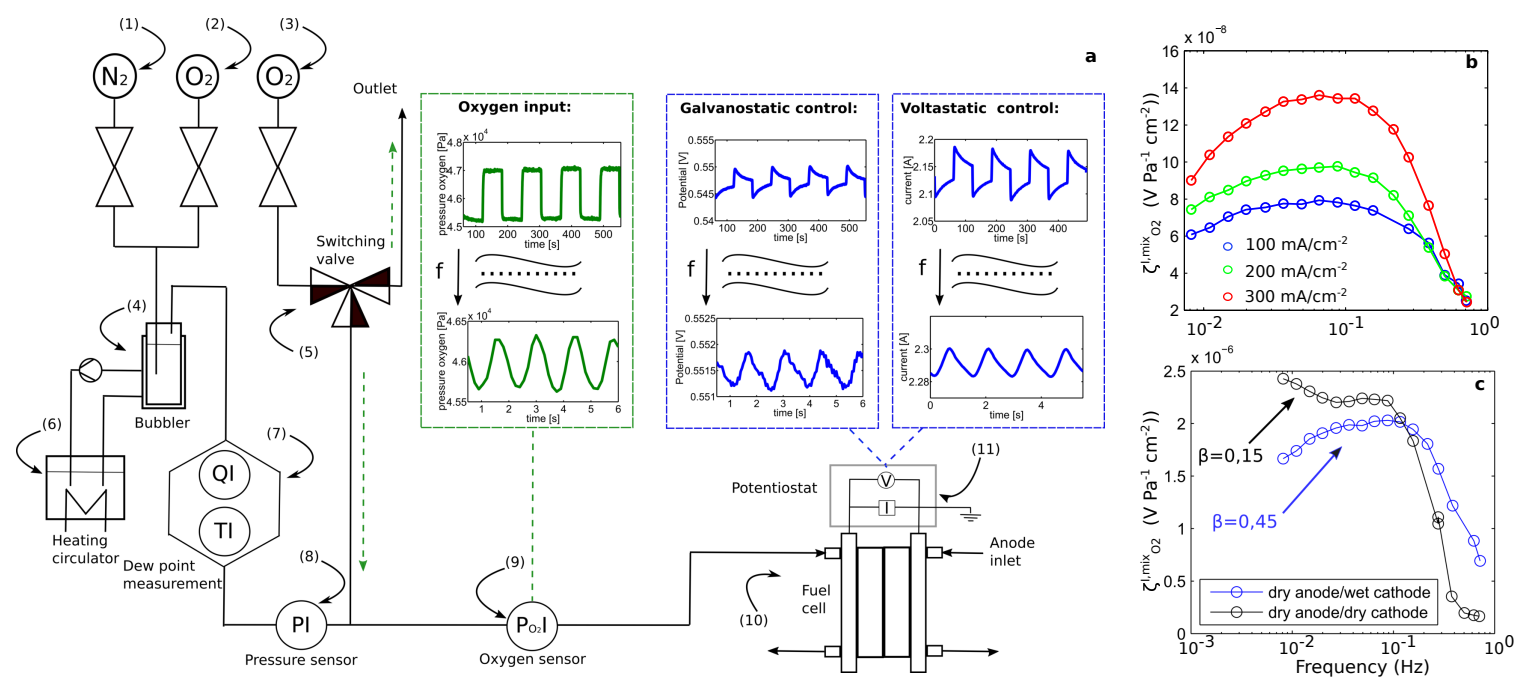

Figure 4. Concentration-alternating FRA (cFRA) technique: (a) Schematic of the cFRA experimental setup, (b) cFRA magnitude Bode plots of $\zeta_{\mathrm{O}_{2}}^{I, m i x}$ at different polarization conditions, and (c) cFRA magnitude Bode plot of $\zeta_{\mathrm{O}_{2}}^{I, m i x}$ at different relative humidity of the feeds. Figures adapted from [17].

In a recent theoretical work, Kulikowski [107] determined an analytical solution to calculate the cFRA oxygen transfer function under galvanostatic conditions $\zeta_{\mathrm{O}_{2}}^{I}$ which is named oxygen impedance. The obtained equation enabled to determine the diffusivity coefficient of oxygen in the GDL and catalyst layer through the minimum point of the imaginary and real part of the Bode plots. It should be mentioned that the cathode gas channel was not included in this mathematical description. Furthermore, the mass transport in the channel was not accounted. According to Sorrentino et al. $[16,17,106]$, these dynamics are the most dominant in the transfer function $\zeta_{\mathrm{O}_{2}}^{I}$.

A couple of novel diagnostic tools for PEMFCs inspired by the concept of TI were proposed. In a new work of Engebretsen et al. [13], the novel electro-thermal impedance spectroscopy (ETIS) has been developed and applied on an open cathode cell as a case study. The technique consists in imposing a periodic electrical stimulus to a fuel cell and in measuring the consequent local surface temperature response through an infrared thermal imaging camera pointed the open cathode flow fields (see Figure $5 \mathrm{a}, \mathrm{b}$ ). In this way, the local heat generation along different regions can be 
dynamically monitored and the thermal conduction properties of the materials and structures can be estimated through determination of the transfer function $Z_{E T I S}$. For example, in the spectra (Figure 5c), the comparison of the ETIS spectra at the channel and at the land positions at different steady state currents indicates that the amplitude ratio of $Z_{E T I S}$ increases as the efficiency of heat dissipation decreases, while the phase plot of the land shifts to a lower frequency due to higher diffusion length with respect to the channel. ETIS allows one to identify current dependent phenomena which change thermal conductivity as water generation and accumulation within the GDL and under land. Conversely, it does not detect current independent effects like hot spots due to pinholes in the membrane that can be identified by DC thermogram. Therefore, ETIS and DC thermography can be considered as complementary techniques.
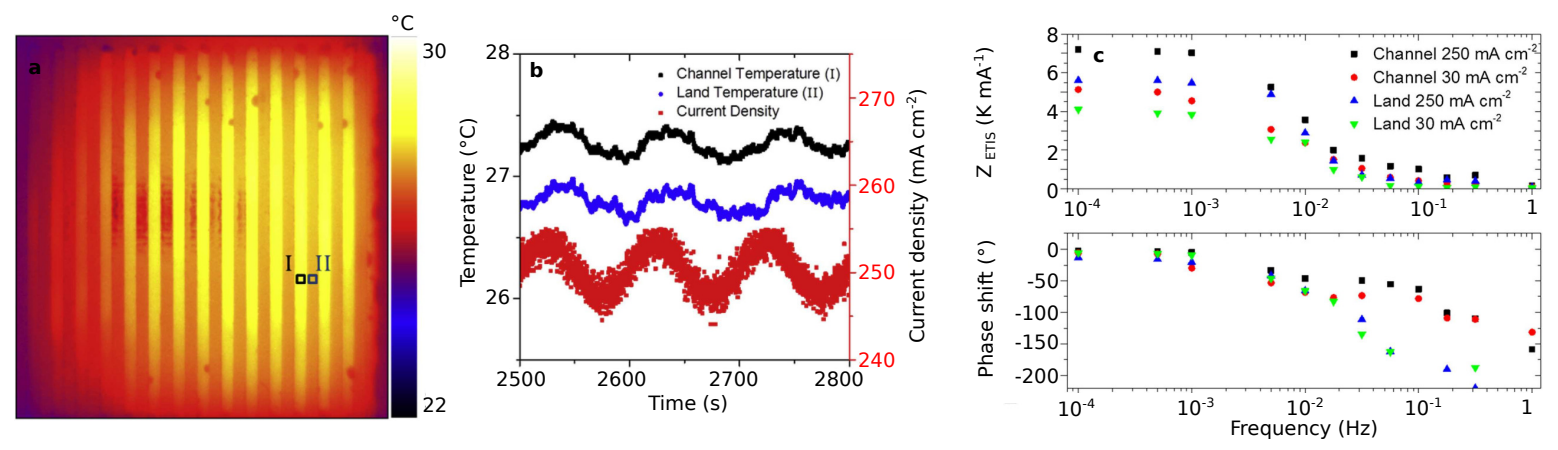

Figure 5. Electro-thermal impedance spectroscopy (ETIS) technique: (a) Thermal infrared image of the open cathode depicting area of the channel (I) and at the land (II), (b) measured current density input and temperature output at the channel (I) and at the land (II) in time domain, and (c) magnitude and phase Bode plots of $Z_{E T I S}$ measured at the channel and at the land at different polarisation currents. Figures taken from reference [13], with permission from Elesevier.

The same group presented another thermography-based FRA technique named lock-in thermography [14]. The main aim of this method is the mapping of water distribution. As depicted in the schematic in Figure 6, this methodology involves the application of a controlled sinusoidal heat pulse on one side of the fuel cell, and the monitoring of the temperature perturbation on the other side of the fuel cell using a thermal imaging camera. By varying the modulation frequency of the imposed heat stimulus, it is possible to observe water build up within the cell through the monitoring of the phase shift between the heat pulse and opposite flow field temperature (Figure 6b). The mapped water distribution at different humidity and steady state current densities are consistent with the results obtained in the literature using neutron imaging. For example, water accumulation in the bends of serpentine flow fields and towards the outlet are detected in the phase spectra Figure $6 \mathrm{c}$. Additionally, it states that the lock-in thermography has the advantage to be substantially cheaper than neutron imaging.

A more accurate frequency response tool to detect water generation is the hydro-electrochemical impedance imaging (HECII) which implies a small sinusoidal current perturbation at different frequencies to the cell, and the measurement of the water thickness variation across the active area obtained using neutron radiography [15]. The measured input and output is displayed in time domain as shown in Figure 7. The distribution of the phase shift and amplitude of the HECII transfer function $Z_{H E C I I}$ at different frequencies indicated the location of liquid water generation (see Figure 7). Comparing the EHCII spatially distributed phase and magnitude at certain frequencies with traditional neutron imaging maps, it is possible to distinguish the legacy of water accumulated in the system over time and water recently generated by reactions. 

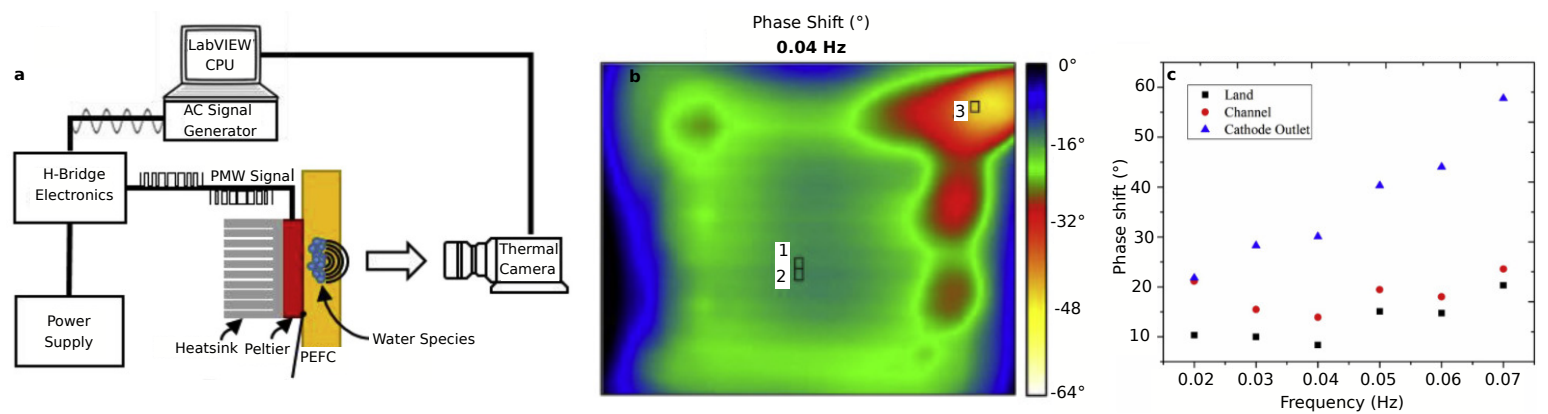

Figure 6. Lock-in thermography technique: (a) Schematic of the setup to peform Lock-in thermography on open cathode PEMFC, (b) spatially distributed phase shift of $Z_{L I T}$ at the frequency of $0.04 \mathrm{~Hz}$, and (c) phase shift Bode plots at different positions in the cell. Figures adapted from [14] with permission from Elsevier.
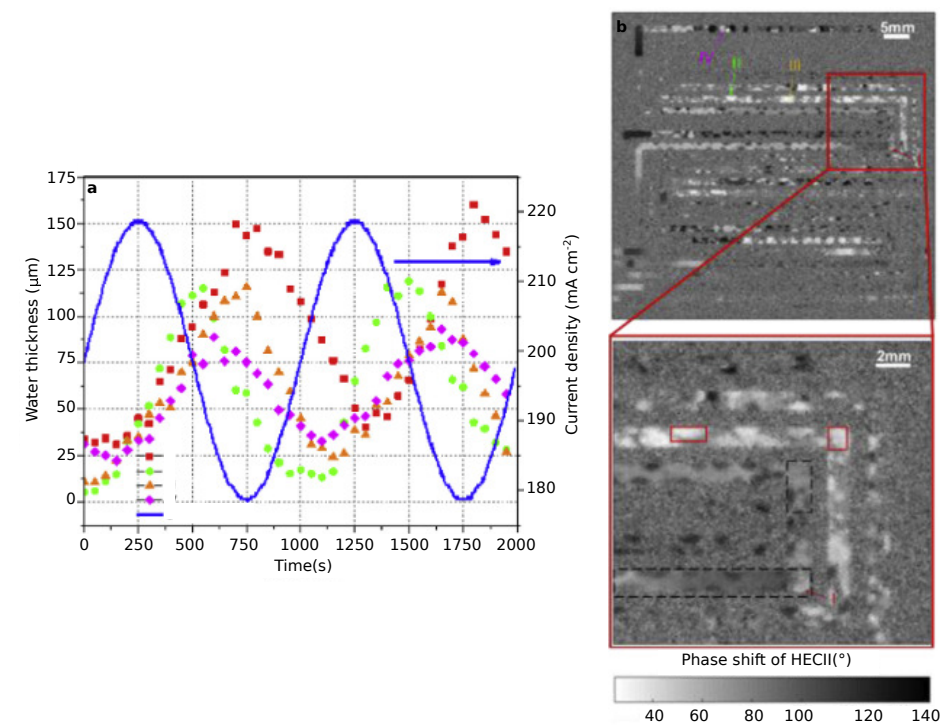

Figure 7. Hydro-electrochemical impedance imaging (HECII) technique: (a) Temporal data of current stimulus (blue) plotted with the water thickness response at four different locations across the active cell area, and (b) HECII over the period 0-2000s. Figures adapted from [15] with permission from Elsevier.

\section{Critical Remarks and Conclusions}

The state-of-the-art FRA methodologies applied to the research and development of PEMFCs was reviewed. At first, different degradation mechanisms that affect PEMFC were discussed. Then, the use of the EIS as a tool supporting the optimisation of fuel cell components and as onboard diagnosis for mobile applications were exposed, as well as challenges related to the interpretation of EIS patterns. Despite the usefulness of this fundamental FRA technique in fuel cell research and development, the complexity of fuel cell dynamics requires the development of diagnostic tools enabling one to detect the dynamics of only targeted processes. In this regard, the novel FRA techniques based on nonelectrical variables have demonstrated to be a valuable instrument allowing one to decouple the contributions of specific phenomena on the PEMFCs performance losses. For example, mass transport, heat transport, and liquid water dynamics were successfully decoupled from other processes respectively performing cFRA, ETIS, and HECII which can contribute to give new insights on PEMFC behaviour. As seen in Table 2, many other input/output configurations still not explored could be easily used for developing new FRA methods, as the instrumentation to measure and control them has been employed in the already existing ones. This suggests that the range of applicability of these novel techniques could be 
further expanded and needs to be explored. However, as their development is at an initial stage, many aspects must be further examined and improved to make them established and solid tools.

First of all, the matter of the linearity of the response has not been approached in most of the literature studies. This is a fundamental issue to asses the reliability of the analysis based on the measured spectra. Engebretsen et al. [12] and Sorrentino et al. [16,17,106] are the only ones who partially addressed this issue. Engebretsen et al. [12] assumed that the amplitude of the voltage response in EPIS satisfied linear constraints, since it was in the same range as in EIS experiments. Therefore, the presence of nonlinearities was excluded. Sorrentino et al. $[16,17,106]$ applied the superposition principle repeating the experiments doubling the amplitude of the concentration input and verifying that the spectra measured was not changing.

Although, ideally both approaches are basically correct, to avoid misleading analysis the eventual external contribution of the instrumentation to the measured transfer function should be verified and if necessary subtracted. These effects could include the response time of the sensor used to monitor the perturbation and output, as well as the additive effects of the fuel cell feed conditioning system which can also be affected by particular perturbations. This was shown by Shirsath et al. [18], who identified that the contribution of the humidifier system affected their measurements in a certain frequency range.

A block diagram of the transfer functions for a generalised FRA setup is depicted in Figure 8. Accordingly, the transfer function $H(i \omega)$ between the input $W(i \omega)$ and output $Y(i \omega)$ read:

$$
H(i \omega)=\frac{Y(i \omega)}{W(i \omega)}=\frac{G_{Y}(i \omega)}{G_{W}(i \omega)} \frac{Y^{*}(i \omega)}{W^{*}(i \omega)} .
$$

The symbols $W^{*}(i \omega)$ and $Y^{*}(i \omega)$ stand respectively for the measured input and output in frequency domain, while the transfer functions $G_{W}(i \omega)$ and $G_{Y}(i \omega)$ contemplate the effect of the instrumentation on the measure of the perturbation and response. Their value can be measured through test experiments on the setup or estimated from the features of instrumentation. An example of this approach is the work of Oliver et al. [108] about the temperature impedance technique.

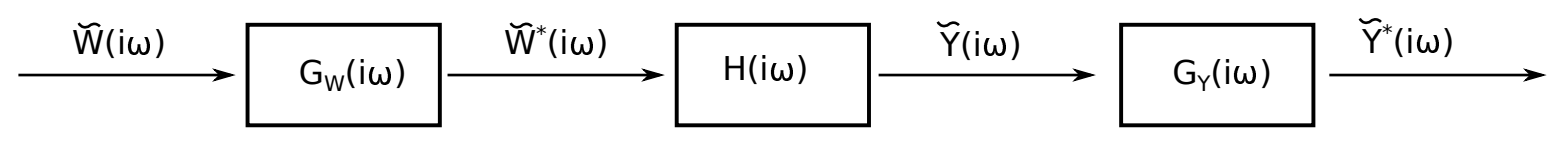

Figure 8. Block diagram of the transfer functions for a general FRA setup.

Another limit encountered in several nonelectrical FRAs is the limit of the available frequency range in the spectra. This limit depends on technical characteristics of the perturbation system which is unable to produce periodic stimulation over a certain frequency value, or it is due to the sampling rate of the sensor which have a restricted capability in the frequency range where the periodic perturbation is monitorable. This limit depends on the time response and frequency sampling of the sensor device. However, it must be mentioned that many reviewed methodologies detect phenomena having low relaxation times like mass transport phenomena and do not require inputs with periodic frequencies higher that $10 \mathrm{~Hz}$.

Finally, the new FRA techniques employable as PEMFC real-time monitoring diagnostic tools should include fast and more flexible procedure to acquire data. In this regard, a possibility could be to use signal processing methodology capable to determine transfer functions from any arbitrary signal rather than only periodic ones that can disturb cell operations, for example wavelet transformation. However, even though the signal acquisition would be fat enough, it must be remarked that most FRA techniques presented could not be implemented on vehicles in the current state as it implies bulky instrumentation and sensors. Among others, the one involving sensors easily implementable are the cFRA and ETIS. 
Author Contributions: Conceptualization: A.S., T.V.-K.; Writing-original draft preparation: A.S.; Writing-review and editing: T.V.-K., K.S.; Supervision: T.V.-K., K.S. All authors have read and agreed to the published version of the manuscript.

Funding: This research received no external funding.

Conflicts of Interest: The authors declare no conflict of interest.

\section{Abbreviations}

The following abbreviations are used in this manuscript:

cFRA Concentration-alternating Frequency Response Analysis

CL Catalyst Layer

EC Equivalent Circuit

ECSA Electrochemically Active Surface Area

EHD Electro-hydrodynamical Impedance

EIS Electrochemical Impedance Spectroscopy

EPIS Electrochemical Pressure Impedance Spectroscopy

ETIS Electrochemical Temperature Impedance Spectroscopy

FRA Frequency Response Analysis

GDL Gas Diffusion Layer

HECII Hydro-electrochemical Impedance Imaging

HOR Hydrogen Oxidation Reaction

LIT Lock-in Thermograpy

LST Linear System Theory

MEA Membrane Electrode Assembly

ORR Oxygen Reduction Reaction

PEMFC Polymer Electrolyte Membrane Fuel Cell

RTD Relaxation Time Distribution

\section{List of Symbols}

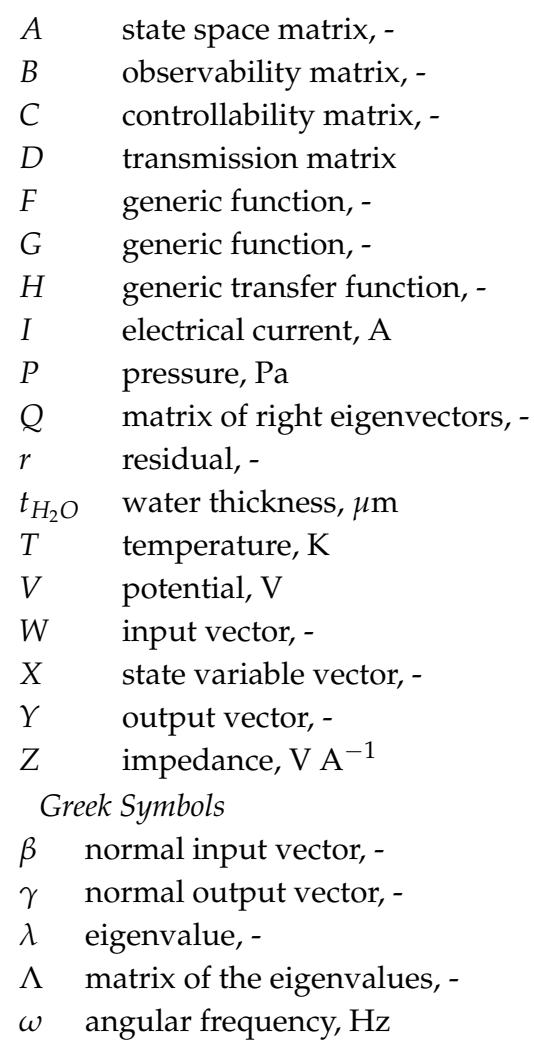




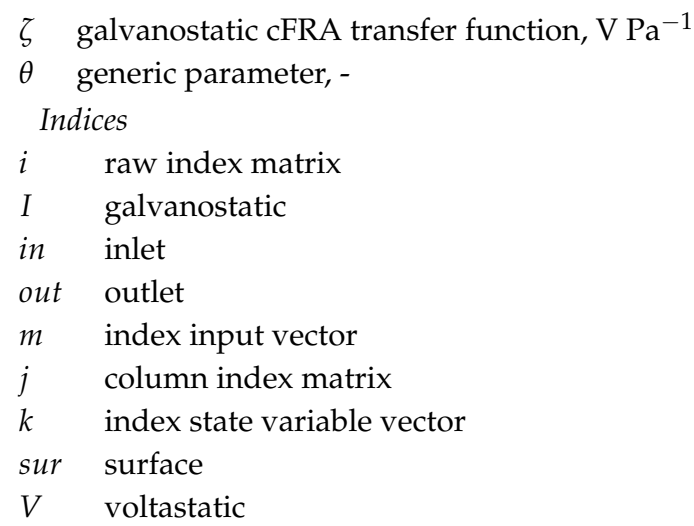

\section{References}

1. Yuan, X.; Wang, H.; Sun, J.C.; Zhang, J. AC impedance technique in PEM fuel cell diagnosis-A review. Int. J. Hydrogen Energy 2007, 32, 4365-4380. [CrossRef]

2. Niya, S.M.R.; Hoorfar, M. Study of proton exchange membrane fuel cells using electrochemical impedance spectroscopy technique-A review. J. Power Sources 2013, 240, 281-293. [CrossRef]

3. Pivac, I.; Barbir, F. Inductive phenomena at low frequencies in impedance spectra of proton exchange membrane fuel cells A review. J. Power Sources 2016, 326, 112-119, [CrossRef]

4. Tang, Z.; Huang, Q.A.; Wang, Y.J.; Zhang, F.; Li, W.; Li, A.; Zhang, L.; Zhang, J. Recent progress in the use of electrochemical impedance spectroscopy for the measurement, monitoring, diagnosis and optimization of proton exchange membrane fuel cell performance. J. Power Sources 2020, 468, 228361, [CrossRef]

5. Weiss, A.; Schindler, S.; Galbiati, S.; Danzer, M.A.; Zeis, R. Distribution of Relaxation Times Analysis of High Temperature PEM Fuel Cell Impedance Spectra. Electrochim. Acta 2017, 230, 391-398. [CrossRef]

6. Mao, Q.; Krewer, U. Total harmonic distortion analysis of oxygen reduction reaction in proton exchange membrane fuel cells. Electrochim. Acta 2013, 103, 188-198. [CrossRef]

7. Kadyk, T.; Hanke-Rauschenbach, R.; Sundmacher, K. Nonlinear frequency response analysis for the diagnosis of carbon monoxide poisoning in PEM fuel cell anodes. J. Appl. Electrochem. 2011, 41, 1021-1032. [CrossRef]

8. Niroumand, A.M.; Merida, W.; Eikerling, M.; Saif, M. Pressure voltage oscillations as a diagnostic tool for PEFC cathodes. Electrochem. Commun. 2010, 12, 122-124.10.1016/j.elecom.2009.11.003. [CrossRef]

9. Niroumand, A.M.; Merida, W.; Saif, M. PEM fuel cell low flow FDI. J. Proc. Control 2011, 21, $602-612$. [CrossRef]

10. Gruebl, D.; Janek, J.; Bessler, W.G. Electrochemical Pressure Impedance Spectroscopy (EPIS) as Diagnostic Method for Electrochemical Cells with Gaseous Reactants: A Model-Based Analysis. J. Electrochem. Soc. 2016, 163, A599-A610. [CrossRef]

11. Hartman, P.; Sommer, H.; Gruebl, D.; Janek, J.; Bessler, W.; Adelhem, P. Pressure dynamics in metal oxygen batteries. J. Phys. Chem. C 2014, 118, 1461-1471. [CrossRef]

12. Engebretsen, E.; Mason, T.J.; Shearing, P.R.; Hinds, G.; Brett, D.J. Electrochemical pressure impedance spectroscopy applied to the study of polymer electrolyte fuel cells. Electrochem. Commun. 2017, 75, 60-63.10.1016/j.elecom.2016.12.014. [CrossRef]

13. Engebretsen, E.; Robinson, J.B.; Obeisun, O.; Mason, T.; Finegan, D.; Hinds, G.; Shearing, P.R.; Brett, D.J. Electrothermal impedance spectroscopy applied to an open-cathode polymer electrolyte fuel cell. J. Power Sources 2016, 302, 210-214. [CrossRef]

14. Rasha, L.; Cho, J.; Neville, T.; Corredera, A.; Shearing, P.; Brett, D. Water distribution mapping in polymer electrolyte fuel cells using lockin thermography. J. Power Sources 2019, 440, 227160. [CrossRef]

15. Wu, Y.; Meyer, Q.; Liu, F.; Rasha, L.; Cho, J.; Neville, T.; Millichamp, J.; Ziesche, R.; Kardjilov, N.; Boillat, P.; et al. Investigation of water generation and accumulation in polymer electrolyte fuel cells using hydroelectrochemical impedance imaging. J. Power Sources 2019, 414, 272-277. [CrossRef]

16. Sorrentino, A.; Vidakovic-Koch, T.; Hanke-Rauschenbach, R.; Sundmacher, K. Concentration-alternating frequency response: A new method for studying polymer electrolyte membrane fuel cell dynamics. Electrochim. Acta 2017, 243, 53-64. [CrossRef] 
17. Sorrentino, A.; Vidakovic-Koch, T.; Sundmacher, K. Studying mass transport dynamics in polymer electrolyte membrane fuel cells using concentration-alternating frequency response analysis. J. Power Sources 2019, 412, 331-335. [CrossRef]

18. Shirsath, A.; Raael, S.; Bonnet, C.; Schiffer, L.; Bessler, W.; Lapicque, F. Electrochemical pressure impedance spectroscopy for investigation of mass transfer in polymer electrolyte membrane fuel cells. Curr. Opin. Electrochem. 2020, 20, 82-87, [CrossRef]

19. Li, H.; Tang, Y.; Wang, Z.; Shi, Z.; Wu, S.; Song, D.; Zhang, J.; Fatih, K.; Zhang, J.; Wang, H.;et al. A review of water flooding issues in the proton exchange membrane fuel cell. J. Power Sources 2008, 178, 103-117. [CrossRef]

20. Ge, S.; Wang, C.Y. Liquid Water Formation and Transport in the PEFC Anode. J. Electrochem. Soc. 2007, 154, B998. [CrossRef]

21. Holmström, N.; Ihonen, J.; Lundblad, A.; Lindbergh, G. The Influence of the Gas Diffusion Layer on Water Management in Polymer Electrolyte Fuel Cells. Fuel Cells 2007, 7, 306-313, [CrossRef]

22. Baumgartner, W.; Parz, P.; Fraser, S.; Wallnoefer, E.; Hacker, V. Polarization study of a PEMFC with four reference electrodes at hydrogen starvation conditions. J. Power Sources 2008, 182, 413-421, [CrossRef]

23. Borup, R.; Meyers, J.; Pivovar, B. Scientific Aspects of Polymer Electrolyte Fuel Cell Durability and Degradation. Chem. Rev. 2007, 107, 2904-3952, [CrossRef]

24. Schulze, M.; Wagner, N.; Kaz, T.; Friedrich, K. Combined electrochemical and surface analysis investigation of degradation processes in polymer electrolyte membrane fuel cells. Electrochim. Acta 2007, 52, 2328-2336, [CrossRef]

25. Taniguchi, A.; Akita, T.; Yasuda, K.; Miyazaki, Y. Analysis of degradation in PEMFC caused by cell reversal during air starvation. Int. J. Hydrogen Energy 2008, 33, 2323-2329. [CrossRef]

26. Liu, Z.; Yang, L.; Mao, Z.; Zhuge, W.; Zhang, Y.; Wang, L. Behavior of PEMFC in starvation. J. Power Sources 2006, 157, 166-176. [CrossRef]

27. Garland, N.L.; Benjamin, T.G.; Kopasz,J.P. Materials issues in polymer electrolyte membrane fuel cells. Mater. Matt. 2008, 3.4, 85.

28. Patterson, T.W.; Darling, R.M. Damage to the Cathode Catalyst of a PEM Fuel Cell Caused by Localized Fuel Starvation. Electrochem. Solid-State Lett. 2006, 9, A183. [CrossRef]

29. Darling, R.M.; Meyers, J.P. Kinetic Model of Platinum Dissolution in PEMFCs. J. Electrochem. Soc. 2003, 150, A1523. [CrossRef]

30. Darling, R.M.; Meyers, J.P. Mathematical Model of Platinum Movement in PEM Fuel Cells. J. Electrochem. Soc. 2005, 152, A242. [CrossRef]

31. Mayrhofer, K.J.; Meier, J.C.; Ashton, S.J.; Wiberg, G.K.; Kraus, F.; Hanzlik, M.; Arenz, M. Fuel cell catalyst degradation on the nanoscale. Electrochem. Commun. 2008, 10, 1144-1147. [CrossRef]

32. Stevens, D.A.; Hicks, M.T.; Haugen, G.M.; Dahn, J.R. Ex Situ and In Situ Stability Studies of PEMFC Catalysts. J. Electrochem. Soc. 2005, 152, A2309. [CrossRef]

33. Roen, L.M.; Paik, C.H.; Jarvi, T.D. Electrocatalytic Corrosion of Carbon Support in PEMFC Cathodes. Electrochem. Solid-State Lett. 2004, 7, A19. [CrossRef]

34. Reiser, C.A.; Bregoli, L.; Patterson, T.W.; Yi, J.S.; Yang, J.D.; Perry, M.L.; Jarvi, T.D. A Reverse-Current Decay Mechanism for Fuel Cells. Electrochem. Solid-State Lett. 2005, 8, A273. [CrossRef]

35. Andreaus, B.; McEvoy, A.J.; Scherer, G.G. Analysis of performance losses in polymer electrolyte fuel cells at high curren density by impedance spectroscopy. Electrochim. Acta 2002, 47, 2223-2229. [CrossRef]

36. Kinumoto, T.; Inaba, M.; Nakayama, Y.; Ogata, K.; Umebayashi, R.; Tasaka, A.; Iriyama, Y.; Abe, T.; Ogumi, Z. Durability of perfluorinated ionomer membrane against hydrogen peroxide. J. Power Sources 2006, 158, 1222-1228, [CrossRef]

37. Laconti, A.; Liu, H.; Mittelsteadt, C.; McDonald, R. Polymer Electrolyte Membrane Degradation Mechanisms in Fuel Cells-Findings Over the Past 30 Years and Comparison with Electrolyzers. ECS Trans. 2019, 1, 199-219. [CrossRef]

38. Natarajan, D.; Van Nguyen, T. Current distribution in PEM fuel cells. Part 1: Oxygen and fuel flow rate effects. AIChE J. 2005, 51, 2587-2598, [CrossRef]

39. Perry, M.L.; Patterson, T.; Reiser, C. Systems Strategies to Mitigate Carbon Corrosion in Fuel Cells. ECS Trans. 2019, 3, 783-795. [CrossRef] 
40. Sung, L.Y.; Hwang, B.J.; Hsueh, K.L.; Tsau, F.H. Effects of anode air bleeding on the performance of CO poisoned proton exchange membrane fuel cells. J. Power Sources 2010, 195, 1630-1639. [CrossRef]

41. Li, H.; Song, C.; Zhang, J.; Zhang, J., Catalyst Contamination in PEM Fuel Cells. In PEM Fuel Cell Electrocatalysts and Catalyst Layers: Fundamentals and Applications; Zhang, J., Ed.; Springer: London, UK, 2008; pp. 331-354. [CrossRef]

42. Halseid, R.; Vie, P.J.; Tunold, R. Effect of ammonia on the performance of polymer electrolyte membrane fuel cells. J. Power Sources 2006, 154, 343-350, [CrossRef]

43. Gabrielli, C.; Tribollet, B. A transfer function approach for a generalized electrochemical impedance spectroscopy. J. Electrochem. Soc. 1994, 141, 1147-1157. [CrossRef]

44. Macdonald, D.D.; Sikora, E.; Engelhardt, G. Characterizing electrochemical systems in the frequency domain. Electrochim. Acta 1998, 43, 87-107. [CrossRef]

45. Collet-Lacoste, J.R. The electrochemical impedance spectroscopy and associated transfer functions: Non-equilibrium thermodynamics consideration. Electrochim. Acta 2004, 49, 4967-4977. [CrossRef]

46. Gajic, Z. Linear Dynamic Systems and Signals; Prentice Hall: Upper Saddle River, NJ, USA, 1980.

47. Kumar, K.S.S. Electric Circuits and Networks; Pearson Education: London, UK, 2008.

48. Athans, M.; Kapasouris, P.; Kappos, E.; Spang, H.A. Linear-quadratic Gaussian with loop-transfer recovering methodology for the F-100 engine. J. Guid. Control Dyn. 1986, 9, 45-52. [CrossRef]

49. Baricci, A.; Mereu, R.; Messaggi, M.; Zago, M.; Inzoli, F.; Casalegno, A. Application of computational fluid dynamics to the analysis of geometrical features in PEM fuel cells flow fields with the aid of impedance spectroscopy. Appl. Energy 2017, 205, 670-682. [CrossRef]

50. Yan, X.; Guan, C.; Zhang, Y.; Jiang, K.; Wei, G.; Cheng, X.; Shen, S.; Zhang, J. Flow field design with 3D geometry for proton exchange membrane fuel cells. Appl. Therm. Eng. 2019, 147, 1107-1114. [CrossRef]

51. Bultel, Y.; Wiezell, K.; Jaouen, F.; Ozil, P.; Lindbergh, G. Investigation of mass transport in gas diffusion layer at the air cathode of a PEMFC. Electrochim. Acta 2005, 51, 474-488. [CrossRef]

52. Atkinson, R.W.; Rodgers, J.A.; Hazard, M.W.; Stroman, R.O.; Gould, B.D. Influence of Cathode Gas Diffusion Media Porosity on Open-Cathode Fuel Cells. J. Electrochem. Soc. 2018, 165, F1002-F1011. [CrossRef]

53. Ihonen, J.; Mikkola, M.; Lindbergh, G. Flooding of Gas Diffusion Backing in PEFCs. J. Electrochem. Soc. 2004, 151, A1152. [CrossRef]

54. Liu, Y.; Ji, C.; Gu, W.; Baker, D.R.; Jorne, J.; Gasteiger, H.A. Proton Conduction in PEM Fuel Cell Cathodes: Effects of Electrode Thickness and Ionomer Equivalent Weight. J. Electrochem. Soc. 2010, 157, B1154. [CrossRef]

55. Lai, Y.C.; Huang, K.L.; Tsai, C.H.; Lee, W.J.; Chen, Y.L. Sputtered Pt loadings of membrane electrode assemblies in proton exchange membrane fuel cells. Int. J. Energy Res. 2012, 36, 918-927, [CrossRef]

56. Moghaddam, R.B.; Easton, E.B. Impedance spectroscopy assessment of catalyst coated Nafion assemblies for proton exchange membrane fuel cells. Electrochim. Acta 2018, 292, 292-298. [CrossRef]

57. Haque, M.A.; Sulong, A.B.; Rosli, R.E.; Majlan, E.H.; Shyuan, L.K.; Mashud, M.A.A. Measurement of hydrogen ion conductivity through proton exchange membrane. In Proceedings of the 2015 IEEE International WIE Conference on Electrical and Computer Engineering (WIECON-ECE), Dhaka, Bangladesh, 19-20 December 2015; pp. 552-555.

58. Abdel-Hady, E.; Abdel-Hamed, M.; Awad, S.; Hmamm, M. Characterization and evaluation of commercial poly (vinylidene fluoride)-g-sulfonatedPolystyrene as proton exchange membrane. Polym. Adv. Technol. 2018, 29, 130-142, [CrossRef]

59. Petrone, R.; Zheng, Z.; Hissel, D.; Péra, M.; Pianese, C.; Sorrentino, M.; Becherif, M.; Yousfi-Steiner, N. A review on model-based diagnosis methodologies for PEMFCs. Int. J. Hydrogen Energy 2013, 38, 7077-7091. [CrossRef]

60. Ciucci, F. Modeling electrochemical impedance spectroscopy. Curr. Opin. Electrochem. 2019, 13, 132-139, [CrossRef]

61. Weber, A.Z.; Borup, R.L.; Darling, R.M.; Das, P.K.; Dursch, T.J.; Gu, W.; Harvey, D.; Kusoglu, A.; Litster, S.; Mench, M.M.; et al. A Critical Review of Modeling Transport Phenomena in Polymer-Electrolyte Fuel Cells. J. Electrochem. Soc. 2014, 161, F1254-F1299. [CrossRef]

62. Chevalier, S.; Auvity, B.; Olivier, J.C.; Josset, C.; Trichet, D.; Machmoum, M. Detection of Cells State-of-Health in PEM Fuel Cell Stack Using EIS Measurements Coupled with Multiphysics Modeling. Fuel Cells 2014, 14, 416-429, [CrossRef] 
63. Goshtasbi, A.; Pence, B.L.; Chen, J.; DeBolt, M.A.; Wang, C.; Waldecker, J.R.; Hirano, S.; Ersal, T. A Mathematical Model toward Real-Time Monitoring of Automotive PEM Fuel Cells. J. Electrochem. Soc. 2020, 167, 024518. [CrossRef]

64. Springer, T.E. Characterization of Polymer Electrolyte Fuel Cells Using AC Impedance Spectroscopy. J. Electrochem. Soc. 1996, 143, 587. [CrossRef]

65. Pivac, I.; Bezmalinovic, D.; Barbir, F. Catalyst degradation diagnostics of proton exchange membrane fuelcells using electrochemical impedance spectroscopy. Int. J. Hydrogen Energy 2018, 43, 13512-13520. [CrossRef]

66. Paganin, V.A.; Oliveira, C.L.F.; Ticianelli, E.A.; Springer, T.E.; Gonzalez, E.R. Modelistic interpretation of the impedance response of a polymer electrolyte fuel cell. Electrochim. Acta 1998, 43, 3761-3766. [CrossRef]

67. Ciurenau, M.; Roberge, R. Parameter identifiability analysis and visualization in large-scale kinetic models of biosystems. J. Phys. Chem. B 2001, 105, 3531-3539.

68. Holmstroem, N.; Wiezell, K.; Lindbergh, G. Studying Low Humidity Effects in PEMFCS using EIS Experiments. J. Electrochem. Soc. 2012, 159, F369-F378. [CrossRef]

69. Parthasarathy, A. The Platinum Microelectrode/Nafion Interface: An Electrochemical Impedance Spectroscopic Analysis of Oxygen Reduction Kinetics and Nafion Characteristics. J. Electrochem. Soc. 1992, 139, 1634. [CrossRef]

70. Kurzweil, P.; Fischle, H.J. A new monitoring method for electrochemical aggregates by impedance spectroscopy. J. Power Sources 2004, 127, 331-340, [CrossRef]

71. Mathias, M.F.; Grot, S.A. System and Method for Controlling Humidity Level of a Fuel Cell. U.S. Patent 6,376,111, 23 April 1990.

72. Yumiya, H.; Kizaki, M.; Asai, H. Toyota Fuel Cell System (TFCS). World Electr. Veh. J. 2015, 7, 85-92. [CrossRef]

73. Nitta, I.; Himanen, O.; Mikkola, M. Contact resistance between gas diffusion layer and catalyst layer of PEM fuel cell. Electrochem. Commun. 2008, 10, 47-51. [CrossRef]

74. Uribe, F.A.; Gottesfeld, S.; Zawodzinski, T.A. Effect of Ammonia as Potential Fuel Impurity on Proton Exchange Membrane Fuel Cell Performance. J. Electrochem. Soc. 2002, 149, A293. [CrossRef]

75. Asghari, S.; Mokmeli, A.; Samavati, M. Study of PEM fuel cell performance by electrochemical impedance spectroscopy. Int. J. Hydrogen Energy 2010, 35, 9283-9290. [CrossRef]

76. Eikerling, M.; Kornyshev, A. Electrochemical impedance of the cathode catalyst layer in polymer electrolyte fuel cells. J. Electroanal. Chem. 1999, 475, 107-123. [CrossRef]

77. Lefebvre, M.C. Characterization of Ionic Conductivity Profiles within Proton Exchange Membrane Fuel Cell Gas Diffusion Electrodes by Impedance Spectroscopy. Electrochem. Solid-State Lett. 1999, 2, 259. [CrossRef]

78. Makharia, R.; Mathias, M.F.; Baker, D.R. Measurement of Catalyst Layer Electrolyte Resistance in PEFCs Using Electrochemical Impedance Spectroscopy. J. Electrochem. Soc. 2005, 152, A970. [CrossRef]

79. Cimenti, M.; Bessarabov, D.; Tam, M.; Stumper, J. Investigation of Proton Transport in the Catalyst Layer of PEM Fuel Cells by Electrochemical Impedance Spectroscopy. ECS Trans. 2019, 28, 147-157. [CrossRef]

80. Kuhn, H.; Wokaun, A.; Scherer, G. Exploring single electrode reactions in polymer electrolyte fuel cells. Electrochim. Acta 2007, 52, 2322-2327, [CrossRef]

81. Wiezell, K.; Gode, P.; Lindbergh, G. Steady-State and EIS Investigations of Hydrogen Electrodes and Membranes in Polymer Electrolyte Fuel Cells. J. Electrochem. Soc. 2006, 153, A749. [CrossRef]

82. Fouquet, N.; Doulet, C.; Nouillant, C.; Dauphin-Tanguy, G.; Ould-Bouamama, B. Model based PEM fuel cell state-of-health monitoring via ac impedance measurements. J. Power Sources 2006, 159, 905-913. [CrossRef]

83. Canut, J.M.L.; Abouatallah, R.M.; Harrington, D.A. Detection of Membrane Drying, Fuel Cell Flooding, and Anode Catalyst Poisoning on PEMFC Stacks by Electrochemical Impedance Spectroscopy. J. Electrochem. Soc. 2006, 153, A857. [CrossRef]

84. Schneider, I.A.; Kramer, D.; Wokaun, A.; Scherer, G.G. Oscillations in the Gas Channels-The Forgotten Player in Impedance Spectroscopy in Polymer Electrolyte Fuel Cells A. Exploring the Wave. ECS Trans. 2006, 3, 1001-1010. [CrossRef]

85. Schneider, I.A.; Freunberger, S.A.; Kramer, D.; Wokaun, A.; Scherer, G.G. Oscillations in Gas Channels. J. Electrochem. Soc. 2007, 154, B383. [CrossRef]

86. Schneider, I.A.; Kramer, D.; Wokaun, A.; Scherer, G.G. Oscillations in Gas Channels. J. Electrochem. Soc. 2007, 154, B770. [CrossRef] 
87. Kulikovsky, A. The effect of stoichiometric ratio on the performance of a polymer electrolyte fuel cell. Electrochim. Acta 2004, 49, 617-625. [CrossRef]

88. Kulikovsky, A.; Shamardina, O. A Model for PEM Fuel Cell Impedance: Oxygen Flow in the Channel Triggers Spatial and Frequency Oscillations of the Local Impedance. J. Electrochem. Soc. 2015, 162, F1068-F1077. [CrossRef]

89. Chandesris, M.; Robin, C.; Gerard, M.; Bultel, Y. Investigation of the difference between the low frequency limit of the impedance spectrum and the slope of the polarization curve. Electrochim. Acta 2015, 180, 581-590. [CrossRef]

90. Keller, S.; Oezel, T.; Scherzer, A.C.; Gerteisen, D.; Gross, U.; Hebling, C.; Manoli, Y. Characteristic Time Constants Derived from Low Frequency Arc of Impedance of Fuel Cell Stack. J. Electrochem. Energy Convers. Storage 2018, 15, 1-10. [CrossRef]

91. Chevalier, S.; Josset, C.; Bazylak, A.; Auvity, B. Measurements of Air Velocities in Polymer Electrolyte Membrane Fuel Cell Channels Using Electrochemical Impedance Spectroscopy. J. Electrochem. Soc. 2016, 163, F816-F823. [CrossRef]

92. Freire, T.J.P.; Gonzalez, E.R. Effect of membrane characteristics and humidification conditions on the impedance response of polymer electrolyte fuel cells. J. Electroanal. Chem. 2001, 503, 57-68. [CrossRef]

93. Wiezell, K.; Holmstroem, N.; Lindbergh, G. Studying Low Humidity Effects in PEMFCs using EIS Modeling. J. Electrochem. Soc. 2012, 159, F379-F392. [CrossRef]

94. Antoine, O.; Bultel, Y.; Durand, R. Oxygen reduction reaction kinetics and mechanism on platinum nanoparticles inside Nafion. J. Electroanal. Chem. 2001, 499, 85-94. [CrossRef]

95. Roy, S.K.; Orazem, M.E.; Tribollet, B. Interpretation of Low-Frequency Inductive Loops in PEM Fuel Cells. J. Electrochem. Soc. 2007, 154, B1378. [CrossRef]

96. Cruz-Manzo, S.; Cruz, C.P.; Greenwood, P.; Chen, R. An impedance model for analysis of EIS of polymer electrolyte fuel cells under platinum oxidation and hydrogen peroxide formation in the cathode. J. Electroanal. Chem. 2016, 771, 94-105. [CrossRef]

97. Franco, A.A.; Tembely, M. Transient Multiscale Modeling of Aging Mechanisms in a PEMFC Cathode. J. Electrochem. Soc. 2007, 154, B712. [CrossRef]

98. Inaba, M.; Yamada, H.; Tokunaga, J.; Tasaka, A. Effect of Agglomeration of Pt C Catalyst on Hydrogen Peroxide Formation. Electrochem. Solid-State Lett. 2004, 7, A474. [CrossRef]

99. Wagner, N.; Schulze, M. Change of electrochemical impedance spectra during CO poisoning of the Pt and Pt Ru anodes in a membrane fuel cell (PEFC). Electrochim. Acta 2003, 48, 3899-3907, doi:10.1016/S0013-4686(03)00528-0. [CrossRef]

100. Schneider, I.A.; Bayer, M.H.; Wokaun, A.; Scherer, G.G. Impedance Response of the Proton Exchange Membrane in Polymer Electrolyte Fuel Cells. J. Electrochem. Soc. 2008, 155, B783.10.1149/1.2929823. [CrossRef]

101. Bao, C.; Bessler, W.G. Two dimensional modeling of a polymer electrolyte membrane fuel cell with long flow channel. Part 2 Physics based electrochemical impedance analysis. J. Power Sources 2015, 278, 675-682. [CrossRef]

102. Setzler, B.P.; Fuller, T.F. A Physics-Based Impedance Model of Proton Exchange Membrane Fuel Cells Exhibiting Low-Frequency Inductive Loops. J. Electrochem. Soc. 2015, 162, F519-F530.10.1149/2.0361506jes. [CrossRef]

103. Benito, D.; Gabrielli, C.; Jareno, J.G.; Keddam, M.; Perrot, H.; Vicente, F. An electrochemical impedance and ac electrogravimetry study of PNR films in aqueous salt media. Electrochem. Commun. 2002, 4, 613-619. [CrossRef]

104. Gabrielli, C.; Jareno, J.G.; Keddam, M.; Perrot, H.; Vicente, F. Ac electrogravimetry study to electroactive thin films. J. Phys. Chem. B 2002, 106, 3182-3191. [CrossRef]

105. Deslouis, C.; Tribollet, B. Recent developments in the electro-hydrodynamic (EHD) impedance technique. J. Electroanal. Chem. 2004, 572, 389-398, [CrossRef]

106. Sorrentino, A.; Sundmacher, K.; Vidakovic-Koch, T. Guide to Concentration Alternating Frequency Response Analysis of Fuel Cells. J. Visual. Exp. 2019, 154, e60129. [CrossRef] 
107. Kulikovsky, A. A model for concentration impedance of a PEM fuel cell. eTransportation 2019, 2, 100026. [CrossRef]

108. Olivier, A.; Merienne, E.; Chopart, J.P.; Aaboubi, O. Thermoelectrochemical impedances 1 . A new experimental device to measure thermoelectrochemical transfer functions. Electrochim. Acta 1992, 37, 1945-1950. [CrossRef]

Publisher's Note: MDPI stays neutral with regard to jurisdictional claims in published maps and institutional affiliations.

(C) 2020 by the authors. Licensee MDPI, Basel, Switzerland. This article is an open access article distributed under the terms and conditions of the Creative Commons Attribution (CC BY) license (http:/ / creativecommons.org/licenses/by/4.0/). 